\title{
Modulation of the Purinergic $\mathrm{P}_{2} \mathrm{X}_{7}$ Receptor Attenuates Lipopolysaccharide-Mediated Microglial Activation and Neuronal Damage in Inflamed Brain
}

\author{
Hyun B. Choi, ${ }^{1,2 \star}$ Jae K. Ryu, ${ }^{1 \star}$ Seung U. Kim, ${ }^{2,3}$ and James G. McLarnon ${ }^{1}$ \\ ${ }^{1}$ Department of Anesthesiology, Pharmacology, and Therapeutics and 2Division of Neurology, Department of Medicine, University of British Columbia, \\ Vancouver, British Columbia, Canada V6T 1Z3, and 3Brain Disease Research Center, Ajou University, Suwon, Korea 443-749
}

\begin{abstract}
We investigated the involvement and roles of the ionotropic purinergic receptor $\mathrm{P} 2 \mathrm{X}_{7} \mathrm{R}$ in microglia in mediating lipopolysaccharide (LPS)-induced inflammatory responses and neuronal damage in rat striatum. A detailed in vivo study showed that LPS injection into striatum markedly increased the expression of $\mathrm{P}_{2} \mathrm{X}_{7} \mathrm{R}$ in microglia compared with control (saline)-injected animals. Additionally, LPS injection upregulated a broad spectrum of proinflammatory mediators, including inducible nitric oxide synthase (nitric oxide production marker), 3-nitrotyrosine (peroxynitrite-mediated nitration marker), 4-hydroxynonenal (lipid peroxidation marker), and 8-hydroxy-2'-deoxyguanosine (oxidative DNA damage marker), and reduced neuronal viability. The $\mathrm{P}_{2} \mathrm{X}_{7} \mathrm{R}$ antagonist oxidized ATP (oxATP) was effective in attenuating expressions of all inflammatory mediators and in addition inhibited LPS-induced activation of the cellular signaling factors $\mathrm{p} 38$ mitogen-activated protein kinase and transcriptional factor nuclear factor $\kappa \mathrm{B}$. Most importantly, in vivo, oxATP blockade of $\mathrm{P} 2 \mathrm{X}_{7} \mathrm{R}$ also reduced numbers of caspase-3-positive neurons and increased neuronal survival in LPS-injected brain. In vitro, LPS stimulation of cultured human microglia enhanced cellular expressions of a host of proinflammatory factors, including cyclooxygenase-2, interleukin-1 $\beta$ (IL-1 $\beta$ ), IL-6, IL-12, and tumor necrosis factor- $\alpha$; all factors were inhibited by oxATP. A novel finding was that LPS potentiated intracellular $\left[\mathrm{Ca}^{2+}\right]_{\mathrm{i}}$ mobilization induced by the $\mathrm{P} 2 \mathrm{X}_{7} \mathrm{R}$ ligand $2^{\prime}, 3^{\prime}-\mathrm{O}-(4$-benzoyl-benzoyl) ATP, which could serve as a mechanistic link for $\mathrm{P} 2 \mathrm{X}_{7} \mathrm{R}$ amplification of inflammatory responses. Our results suggest critical roles for $\mathrm{P} 2 \mathrm{X}_{7} \mathrm{R}$ in $\mathrm{mediating}$ inflammation and inhibition of this subtype purinergic receptor as a novel therapeutic approach to reduce microglial activation and confer neuroprotection in inflamed and diseased brain.
\end{abstract}

Key words: $\mathrm{P} 2 \mathrm{X}_{7}$ receptor; lipopolysaccharide; microglia; inflammation; cytokines; oxidized ATP

\section{Introduction}

Inflammation is a critical component in the progressive neurodegeneration manifest in neurological disorders. The activation of glial cells, microglia, and astrocytes is a characteristic finding in brain inflammation. Microglia, as the immunocompetent resident cells of the brain, possess properties particularly suitable in mediating cellular inflammatory responses. The release of proinflammatory mediators from activated microglia has been suggested as a contributing factor to pathology in disease (McGeer and McGeer, 1998; Lue et al., 2001; Walker et al., 2001), with anti-inflammatory agents conferring some degree of neuroprotection (Suzuki et al., 2004; Klegeris and McGeer, 2005). An important aspect in the induction of an inflammatory response may

\footnotetext{
Received Dec. 14, 2006; revised March 13, 2007; accepted March 28, 2007.

This work was supported by a doctoral research award from the Heart and Stroke Foundation of Canada (H.B.C.) and grants from the Pacific Alzheimer Research Foundation (J.G.M.), Alzheimer's Association USA (J.G.M.), and Korea Science and Engineering Foundation/Brain Disease Research Center (S.U.K.).

*H.B.C. and J.K.R. contributed equally to this work.

Correspondence should be addressed to Dr. James G. McLarnon, Department of Anesthesiology, Pharmacology, and Therapeutics, University of British Columbia, 2176 Health Sciences Mall, Vancouver, British Columbia, Canada V6T 1Z3. E-mail: mclarnon@interchange.ubc.ca.

DOI:10.1523/JNEUROSCI.5417-06.2007

Copyright $\odot 2007$ Society for Neuroscience $\quad$ 0270-6474/07/274957-12\$15.00/0
}

be a signal from damaged neurons to activate microglia. In this regard, evidence is available to indicate that increased levels of extracellular ATP can mobilize and activate microglia under pathological conditions associated with spinal cord injury and ischemia (Le Feuvre et al., 2002; Franke et al., 2004; Wang et al., 2004).

Microglia (and astrocytes) express purinergic receptors for the two receptor subfamilies, ionotropic (P2XR) and metabotropic (P2YR), which mediate mobilization of intracellular $\mathrm{Ca}^{2+}$ $\left[\mathrm{Ca}^{2+}\right]_{\mathrm{i}}$ (Moller, 2002; McLarnon, 2005). A particularly interesting member of the P2XR family is $\mathrm{P} 2 \mathrm{X}_{7} \mathrm{R}$, principally expressed by macrophage-like cells of the brain and linked with a high conductance pore. Activation of $\mathrm{P} 2 \mathrm{X}_{7} \mathrm{R}$ generally requires elevated levels of extracellular ATP (in excess of $1 \mathrm{mM}$ ), suggesting an involvement in pathophysiological conditions. During activation, $\mathrm{P} 2 \mathrm{X}_{7} \mathrm{R}$ mediates influx of $\mathrm{Na}^{+}$and $\mathrm{Ca}^{2+}$ and concomitant efflux of $\mathrm{K}^{+}$, which in microglia helps shape and modulate a diversity of cellular inflammatory responses (Gudipaty et al., 2003; Witting et al., 2004).

Functionally, $\mathrm{P} 2 \mathrm{X}_{7} \mathrm{R}$ plays a critical role in microglial release of the proinflammatory cytokine interleukin- $1 \beta$ (IL- $1 \beta$ ) by reducing intracellular levels of $\mathrm{K}^{+}$(Ferrari et al., 1999; Humphreys et al., 2000; Rothwell and Luheshi, 2000). Increased levels of 
IL- $1 \beta$ are implicated in the pathogenesis of neurodegenerative diseases such as Alzheimer's disease (AD), multiple sclerosis, and Parkinson's disease (Griffin and Mrak, 2002; Li et al., 2003; Ferrari et al., 2006). Recent work has reported that activation of $\mathrm{P} 2 \mathrm{X}_{7} \mathrm{R}$ in microglia led to an increased production of superoxide anion $\left(\mathrm{O}_{2}{ }^{-}\right)$in a transgenic Tg2576 mouse model of AD (Parvathenani et al., 2003). Application of the $\mathrm{P} 2 \mathrm{X}_{7} \mathrm{R}$ ligand $2^{\prime}, 3^{\prime}-\mathrm{O}-(4-$ benzoyl-benzoyl) ATP (BzATP) increases the production of proinflammatory cytokines from macrophages and microglial cells (Rampe et al., 2004), with the specific $\mathrm{P}_{2} \mathrm{X}_{7} \mathrm{R}$ antagonist oxidized ATP (oxATP) reported effective against neuronal damage (Wang et al., 2004).

In this study, we investigated the roles of $\mathrm{P} 2 \mathrm{X}_{7} \mathrm{R}$ in linking inflammatory responses with neuronal damage in a lipopolysaccharide (LPS) animal model of inflammation and in vitro in LPSstimulated human microglia. The overall findings suggest critical functions for microglial $\mathrm{P} 2 \mathrm{X}_{7} \mathrm{R}$-mediated oxidative stress and proinflammatory responses in causing neuronal loss in inflamed striatal brain. Importantly, inhibition of $\mathrm{P}_{2} \mathrm{X}_{7} \mathrm{R}$ in microglia has been found effective in reducing a broad spectrum of inflammatory responses and conferring neuroprotection in inflamed brain. Furthermore, our results suggest that pharmacological modulation of $\left[\mathrm{Ca}^{2+}\right]_{\mathrm{i}}$ mobilization mediated by $\mathrm{P} 2 \mathrm{X}_{7} \mathrm{R}$ in activated microglia may underlie the neuroprotective effects.

\section{Materials and Methods}

Animals. All animal experiments were performed in accordance with the guidelines set by the Committee on Animal Research at the University of British Columbia. Male Sprague Dawley rats (240-260 g) were anesthetized with sodium pentobarbital (50 mg/kg, i.p.) and then mounted in a stereotaxic apparatus (David Kopf Instruments, Tujunga, CA). Animals received unilateral stereotaxic injection of $5 \mu \mathrm{g}$ of LPS (Sigma, St. Louis, $\mathrm{MO}$ ) dissolved in PBS over $4 \mathrm{~min}$ at the following coordinates: anteroposterior $(\mathrm{AP}),+1.0 \mathrm{~mm}$; mediolateral $(\mathrm{ML}),-2.6 \mathrm{~mm}$; dorsoventral (DV), $-5.0 \mathrm{~mm}$ (Paxinos and Watson, 1998). oxATP (Sigma) was dissolved in water and further diluted to PBS, and animals received intracerebroventricular injections (coordinates: $\mathrm{AP},+0.48 \mathrm{~mm}$; $\mathrm{ML},-1.0 \mathrm{~mm}$; DV,$-3.8 \mathrm{~mm}) 30 \mathrm{~min}$ before LPS injection. Control animals received intracerebroventricular injections of PBS; another group received intracerebroventricular injections of oxATP alone. The animals were deeply anesthetized at $6 \mathrm{~h}, 12 \mathrm{~h}, 24 \mathrm{~h}$, or $3 \mathrm{~d}$ after LPS injection and transcardially perfused with heparinized saline, followed by $4 \%$ paraformaldehyde for additional analysis. For systemic administration of LPS, animals intraperitoneally received two concentrations of LPS $(0.5 \mathrm{or} 5 \mathrm{mg} / \mathrm{kg})$. Animals that received LPS were killed at $1 \mathrm{~d}$ after LPS injection.

Cell culture. The methods used in the isolation and identification of microglia have been described previously (Nagai et al., 2001). In brief, human embryonic brain tissues (12-18 weeks of gestation) were dissected into small blocks, incubated in PBS containing $0.25 \%$ trypsin and $40 \mu \mathrm{g} / \mathrm{ml} \mathrm{DNase}$ for $30 \mathrm{~min}$ at $37^{\circ} \mathrm{C}$, and dissociated into single cells by repeated pipetting. Dissociated cells were plated in T75 flasks in a medium consisting of DMEM with high glucose containing 5\% horse serum, $25 \mu \mathrm{g} / \mathrm{ml}$ gentamicin, and $2.5 \mu \mathrm{g} / \mathrm{ml}$ amphotericin B. Freely floating microglia were harvested from a medium of mixed cell cultures after $7-10 \mathrm{~d}$ of growth in culture flasks. Immunostaining with CD11b and Ricinus communis agglutinin, specific markers for microglia, ensured that the purity of cultures was in excess of $98 \%$. The use of embryonic human tissues was approved by the Clinical Screening Committee for Human Subjects of the University of British Columbia.

Immunohistochemistry. Free-floating sections ( $40 \mu \mathrm{m}$ serial coronal sections) were processed for immunostaining as described previously (Ryu et al., 2003). To ensure striatal sections were matched between groups, anatomical landmarks provided by the brain atlas (Paxinos and Watson, 1998) were used for tissue selection. The primary antibodies used for immunostaining were as follows: neuronal-specific nuclear protein (NeuN) for neurons (1:500; Chemicon, Temecula, CA), OX-42 for microglia (1:400; Serotec, Oxford, UK), GFAP for astrocytes (1:500; Sigma), $\mathrm{P}_{2} \mathrm{X}_{7} \mathrm{R}$ (1:200; Alomone Labs, Jerusalem, Israel), 3-nitrotyrosine (3-NT) (1:500; Upstate Biotechnology, Lake Placid, NY), 4-hydroxynonenal (4-HNE) (1:500; Jaica, Shizuoka, Japan), 8-hydroxy2 '-deoxyguanosine (8-OHdG) (1:500; Jaica), inducible nitric oxide synthase (iNOS) (1:100; Upstate Biotechnology), and cleaved caspase-3 (1: 200; Cell Signaling Technology, Beverly, MA). Phospho-p38 mitogenactivated protein kinase (MAPK) (1:250; Cell Signaling Technology) and p65 subunit of nuclear factor $\kappa \mathrm{B}(\mathrm{NF} \kappa \mathrm{B})$ (1:250; Santa Cruz Biotechnology, Santa Cruz, CA) were used for intracellular signaling markers. Sections were incubated at room temperature $\left(20-22^{\circ} \mathrm{C}\right)$ for $2 \mathrm{~h}$ in biotinylated anti-mouse/rabbit IgG (1:200; Vector Laboratories, Burlingame, CA) followed by an ABC elite system (1:200; Vector Laboratories) for $1 \mathrm{~h}$. The reaction products were developed using a DAB kit (Sigma). Alexa Fluor 594 anti-rabbit and Alexa Fluor 488 anti-mouse IgG (1:100) secondary antibodies (Invitrogen, Carlsbad, CA) were used for immunofluorescent staining. For each immunohistochemical staining, the primary antibody was omitted to assess for nonspecific binding of the secondary antibody. For 3-NT immunohistochemistry, positive (use of $24 \mathrm{~mm}$ peroxynitrite) and negative (use of $10 \mathrm{~mm}$ nitrotyrosine) controls were performed (Ayata et al., 1997).

Reverse transcriptase-PCR. For in vivo experiments, brains were removed and the striatum was dissected onto a cold metal tissue matrix (Harvard Apparatus, Montreal, Quebec, Canada). Total RNA was then extracted from striatal tissue using TRIzol reagent (Invitrogen) subjected to DNase I treatment, and complementary DNA synthesis was performed using Moloney murine leukemia virus reverse transcriptase (RT) (Invitrogen). Reverse transcriptase was omitted as a negative control. For in vitro experiments, human microglia were incubated in serum-free medium for $48 \mathrm{~h}$. This procedure yielded a homogeneous population of cells with ramified, process-bearing morphology. PCR primers are all intron spanning, and sequences and expected product sizes are listed in Table 1. PCR conditions were as follows: initial denaturation at $95^{\circ} \mathrm{C}$ for 6 min followed by 35 cycles of denaturation at $95^{\circ} \mathrm{C}$ for $45 \mathrm{~s}$, annealing at $55-60^{\circ} \mathrm{C}$ for $1 \mathrm{~min}$, and extension at $72^{\circ} \mathrm{C}$ for $1 \mathrm{~min}$. A final extension was performed at $72^{\circ} \mathrm{C}$ for $10 \mathrm{~min}$. Glyceraldehyde-3-phosphate dehydrogenase (GAPDH) and $\beta$-actin were used as reaction standards for human and rat samples, respectively. The amplified DNAs were identified using $1.5 \%$ agarose gels containing ethidium bromide and visualized under UV light. The band intensities of PCR products in control and with stimuli were measured using NIH Image J 1.24 software and expressed as relative mRNA levels (mRNA values normalized to GAPDH or $\beta$-actin).

$\mathrm{Ca}^{2+}$ spectrofluorometry. The procedures used in $\mathrm{Ca}^{2+}$-sensitive fluorescence microscopy in this laboratory have been described previously (Khoo et al., 2001; McLarnon et al., 2001). In brief, the fluorescent $\mathrm{Ca}^{2+}$ indicator fura 2-AM was added with pluronic acid (both agents at $1 \mu \mathrm{M}$ ) to cultured human microglia bathed in physiological saline solution (PSS) at room temperature for $30 \mathrm{~min}$. PSS contained the following (in $\mathrm{mm}$ ): $126 \mathrm{NaCl}, 5 \mathrm{KCl}, 1 \mathrm{CaCl}_{2}, 1.2 \mathrm{MgCl}_{2}, 10 \mathrm{HEPES}$, and $10 \mathrm{D}$-glucose, $\mathrm{pH}$ 7.4. $\mathrm{Ca}^{2+}$-free PSS contains the same ionic composition as PSS with the exception that it included EGTA (at $1 \mathrm{~mm}$ ) with no added $\mathrm{CaCl}_{2}$. Cells were washed for $10 \mathrm{~min}$ in dye-free PSS. Coverslips were placed on the stage of an inverted microscope (Axiovert with $40 \times$ quartz objective; Zeiss, Oberkochen, Germany), and alternating 340 and $380 \mathrm{~nm}$ UV light was used for excitation. Fluorescent signals were recorded by passing 510 $\mathrm{nm}$ of emission light (bandwidth of $40 \mathrm{~nm}$ ) to a digital CCD camera (Retiga 1300i; QImaging, Burnaby, British Columbia, Canada). An imaging system (Empix, Mississauga, Ontario, Canada) was used to process and analyze fluorescent signals based on the wavelength ratios (340/380 $\mathrm{nm})$, and ratio images were processed every $6 \mathrm{~s}$. In $\mathrm{Mn}^{2+}$ quenching studies, the divalent cation $\mathrm{Mn}^{2+}$ (at $25 \mu \mathrm{M}$ ) was added to the $\mathrm{Ca}^{2+}$-free PSS. In the quenching experiments, an excitation wavelength of $360 \mathrm{~nm}$ was used because this wavelength corresponds closely to the isosbestic point of the fura 2-AM spectrum. All imaging experiments were done at room temperature.

Quantitative analysis. The four immunostained sections (AP, +1.4 , $+1.2,+1.0$, and +0.8 ) were digitized and analyzed using image analysis program NIH version 1.57 (Wayne Rasband, National Institutes of Health, Bethesda, MD) as described previously (Ryu et al., 2004). Quan- 
Table 1. Gene-specific PCR primer sequences

\begin{tabular}{|c|c|c|c|}
\hline Gene & & Sequence $\left(5^{\prime}-3^{\prime}\right)$ & Product size (bp) \\
\hline COX-2 & Sense & TTCAAATGAGATTGTGGGAAAATTGCT & 305 \\
\hline $\operatorname{cox}-2$ & Antisense & AGATCATCTCTGCCTGAGTATCTT & \\
\hline GAPDH & Sense & CCATGTTCGTCATGGGTGTGAACCA & 251 \\
\hline GAPDH & Antisense & GCCAGTAGAGGCAGGGATGATGTTC & \\
\hline $\mathrm{IL}-1 \beta$ & Sense & AAAAGCTTGGTGATGTCTGG & 179 \\
\hline IL-1 $\beta$ & Antisense & TTTCAACACGCAGGACAGG & \\
\hline IL-6 & Sense & GTGTGAAAGCAGCAAAGAGGC & 159 \\
\hline IL-6 & Antisense & CTGGAGGTACTCTAGGTATAC & \\
\hline IL-8 & Sense & ATGACTTCCAAGCTGGCCGTG & 301 \\
\hline IL-8 & Antisense & TATGAATTCTCAGCCCTCTTCAAAA & \\
\hline IL-10 & Sense & GATCTCCGAGATGCCTTCAGCAGA & 194 \\
\hline IL-10 & Antisense & CCTTGATGTCTGGGTCTTGGTTCT & \\
\hline IL-12 & Sense & TCACAAAGGAGGCGAGGTTCTAAGC & 213 \\
\hline IL-12 & Antisense & CCTCTGCTGCTTTTGACACTGAATG & \\
\hline MCP-1 & Sense & ACTGAAGCTCGCACTCTC & 348 \\
\hline MCP-1 & Antisense & CTTGGGTTGTGGAGTGAG & \\
\hline$P 2 X_{7} R$ & Sense & ACAATGTTGAGAAACGGACTCTGA & 728 \\
\hline$P 2 X_{7} R$ & Antisense & CCGGCTGTTGGTGGAATCCACATC & \\
\hline TGF- $\beta 1$ & Sense & TTGCAGTGTGTTATCCGTGCTGTC & 185 \\
\hline TGF- $\beta 1$ & Antisense & CAGAAATACAGCAACAATTCCTGG & \\
\hline TNF- $\alpha$ & Sense & CAAAGTAGACCTGCCCAGAC & 490 \\
\hline TNF- $\alpha$ & Antisense & GACCTCTCTCTAATCAGCCC & \\
\hline$\beta$-Actin (r) & Sense & GTG GGG CGC CCC AGG CAC CA & 526 \\
\hline$\beta$-Actin (r) & Antisense & GTCCTTAATGTCACGCACGATTTC & \\
\hline iNOS (r) & Sense & CCTGCCCCTTCAATGGT & 758 \\
\hline iNOS (r) & Antisense & GGTATGCCCGAGTTCTTT & \\
\hline$P 2 X_{7} R(r)$ & Sense & AGGAGCCCCTTATCAGCTCT & 692 \\
\hline$P 2 X_{7} R(r)$ & Antisense & CATTGGTGTACTTGTCGTCC & \\
\hline
\end{tabular}

(r), Rat-specific primers. Other primers are human-specific sequences.

A

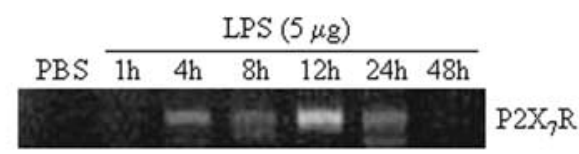

$\mathrm{C}$

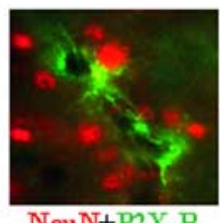

$\mathrm{NeuN}+\mathrm{P} 2 \mathrm{X}_{7} \mathrm{R}$

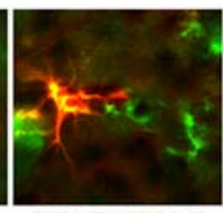

$\mathrm{GFAP}+\mathrm{P} 2 \mathrm{X}_{7} \mathrm{R}$

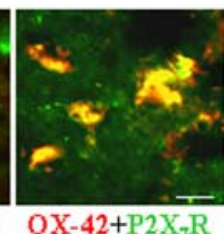

$\mathrm{OX}-42+\mathrm{P} 2 \mathrm{X}_{7} \mathrm{R}$
B

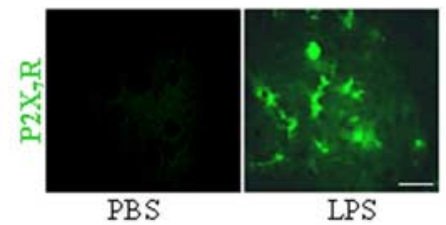

$\mathrm{D}$

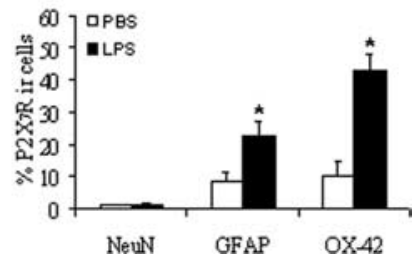

Figure 1. LPS induces expression of $P 2 X_{7} R$ in rat striatum. $A$, LPS injection $(5 \mu \mathrm{g})$ into rat striatum induced time-dependent expression of $\mathrm{P} 2 \mathrm{X}_{7} \mathrm{R}$ mRNA, showing maximum levels at $12 \mathrm{~h}$ after injection. $\boldsymbol{B}$, Brain sections were immunostained with $\mathrm{P} 2 \mathrm{X}_{7} \mathrm{R}$ antibody 24 hafter injection with PBS (left) or LPS (right). P2X $\mathrm{R}^{+}{ }^{+}$cells are shown in green. Scale bar, $25 \mu \mathrm{m}$. C, Brain tissues were double immunostained using cell-selective markers NeuN (for neurons; left), GFAP (for astrocytes; middle), and OX-42 (for microglia; right) $24 \mathrm{~h}$ after $L P S$ injection into rat striatum. (ell-specific markers are presented in red, and P2X $X_{7} R$ is shown in green. Scale bar, $20 \mu \mathrm{m}$. D, The bar graph shows percentage of $P 2 X_{7} R^{+}$cells colocalized with cell-selective markers NeuN, GFAP, and 0X-42 after PBS or LPS injection into rat striatum ( $n=4$ animals). ${ }^{*} p<0.05$ compared with PBS-injected striatum.

tification of neuronal damage in the striatum was performed by counting neurons double stained with NeuN and caspase-3 using a Zeiss Axioplan 2 fluorescent microscope ( $40 \times$ objective). The number of NeuNpositive $\left(\mathrm{NeuN}^{+}\right)$and caspase- $3^{+}$cells was counted and expressed as caspase-3-immunoreactive neurons per square millimeter. The number of $\mathrm{NeuN}^{+}$cells were counted for treated and control groups to determine neuronal loss. OX-42-immunoreactive cells were counted for the measurement of microglial activation. For quantification of p38 MAPK, double staining of OX- $42^{+}$microglia with phospho-p38 MAPK was measured. The number of cells expressing phospho-p38 MAPK was then presented as cells per square millimeter. For NF $\kappa$ B, sections were immunostained with the p65 subunit of the transcription factor and counterstained with 4',6-diamidino-2-phenylindole for cellular nuclei. Microglia expressing $\mathrm{NF} \kappa \mathrm{B}$ were counted for quantification of the transcription factor and presented as cells per square millimeter. For the measurement of oxidative stress, areas containing 4-HNE- or 8-OHdGimmunostained cells were sharply delineated, measured in four sections of the striatum, and expressed as 4-HNE- or 8-OHdGimmunoreactive areas. For the quantification of iNOS and 3-NT, immunoreactive cells were counted from four different affected areas of the striatum. Quantitative analyses were done in a blinded manner.

Statistics and analysis. All results are expressed as means \pm SEM. Statistical significance of differences for among group comparisons was evaluated using one-way ANOVA followed by Newman-Keuls post hoc multiple comparison test (Prism 3.0; GraphPad Software, San Diego, CA). Significance levels were set at $p<0.05$ for all tests.

\section{Results}

Effects of LPS on P2X $\mathrm{X}_{7} \mathrm{R}$ expression and colocalization in rat brain

We initially examined the effects of LPS on $\mathrm{P} 2 \mathrm{X}_{7} \mathrm{R}$ expression in rat brain using $\mathrm{RT}$ PCR and immunohistochemical analysis. LPS ( $5 \mu \mathrm{g})$ was injected into rat striatum, and expression of $\mathrm{P} 2 \mathrm{X}_{7} \mathrm{R}$ was determined at different postinjection time points $(1,4$, 8, 12, 24, 48 h). Representative RT-PCR results (Fig. 1A) showed no evident $\mathrm{P} 2 \mathrm{X}_{7} \mathrm{R}$ in control (12 h after injection of $\mathrm{PBS})$. However, $\mathrm{P} 2 \mathrm{X}_{7} \mathrm{R}$ increased in a time-dependent manner to a maximum level at $12 \mathrm{~h}$ after injection of LPS. Little or no expression of the purinergic receptor was found at the longest time of $48 \mathrm{~h}$ after LPS injection.

Significant upregulation of $\mathrm{P} 2 \mathrm{X}_{7} \mathrm{R}$ expression was found at $24 \mathrm{~h}$ after LPS injection by immunohistochemical analysis (Fig. $1 B$ ). In control striatum, PBS (at $24 \mathrm{~h}$ ) injection induced little or no $\mathrm{P} 2 \mathrm{X}_{7} \mathrm{R}$ expression (Fig. 1B, left). However, LPS injection (Fig. $1 B$, right, green staining) markedly upregulated expression of $\mathrm{P} 2 \mathrm{X}_{7} \mathrm{R}$ compared with PBS-injected striatum. Overall, immunoreactivities (IR) to $\mathrm{P} 2 \mathrm{X}_{7} \mathrm{R}$ for PBS and LPS-injected groups were $1.0 \pm 0.5$ and $36.0 \pm 3.8 / \mathrm{mm}^{2}$, respectively ( $n=4$ animals). These results show marked upregulation of $\mathrm{P} 2 \mathrm{X}_{7} \mathrm{R}$ in the presence of LPS.

The next set of experiments examined cellular expression of $\mathrm{P} 2 \mathrm{X}_{7} \mathrm{R}$ at $24 \mathrm{~h}$ after injection of LPS (or PBS as control) using double immunostaining for cell-specific markers (NeuN for neurons, GFAP for astrocytes, OX-42 for microglia; red cellular staining) with $\mathrm{P}_{2} \mathrm{X}_{7} \mathrm{R}$ (green staining). A representative staining 
A

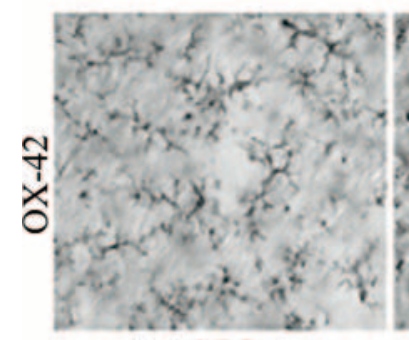

PBS

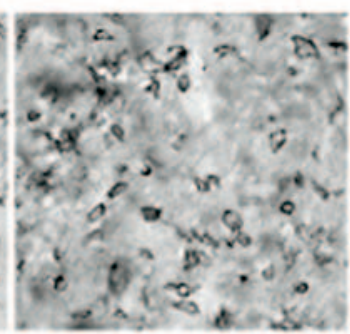

LPS

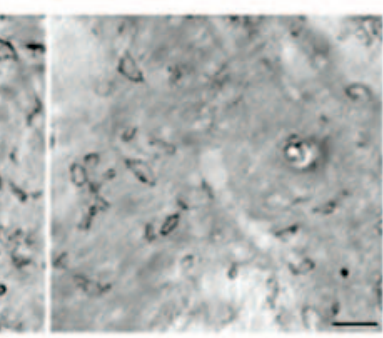

LPS + oxATP
B

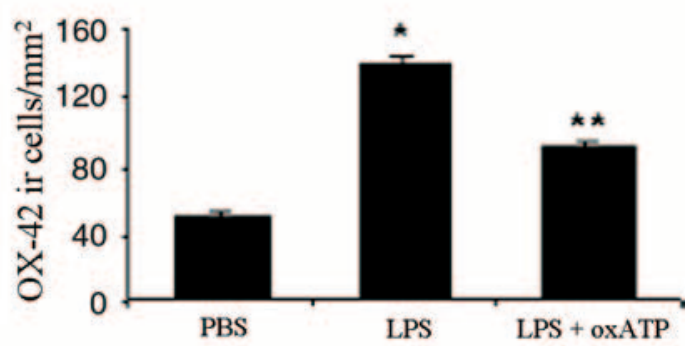

Figure 2. oxATP reduces the number of activated microglia in LPS-injected ( $5 \mu \mathrm{g}$ for $3 \mathrm{~d}$ ) rat brain. $\boldsymbol{A}$, Brain sections were immunostained with $0 \mathrm{X}$ - 42 antibody after injection with PBS (left), LPS (middle), or LPS with oxATP (right). Scale bar, $25 \mu \mathrm{m}$. B. The bar graph shows the number of 0X-42 IR cells after PBS, LPS, or LPS plus oxATP injection ( $n=5$ animals). * $p<0.05$ compared with PBS-injected group; ${ }^{* *} p<0.05$ compared with LPS-injected group.

pattern is presented in Figure $1 C$ showing that LPS induced a predominant colocalization of $\mathrm{P} 2 \mathrm{X}_{7} \mathrm{R}$ with microglia (right panel) and to a lesser extent with astrocytes (middle panel); no evident immunostaining for $\mathrm{P}_{2} \mathrm{X}_{7} \mathrm{R}$ was found in neurons (left panel).

Quantification of cellular $\mathrm{P} 2 \mathrm{X}_{7} \mathrm{R}$ IR is shown in Figure $1 \mathrm{D}$ ( $n=4$ animals). With LPS injection, the maximum $\mathrm{P}_{2} \mathrm{X}_{7} \mathrm{R}$ IR was found in microglia ( $42.7 \%$ of OX $-42^{+}$microglia) with a lesser IR measured in astrocytes $\left(22.5 \%\right.$ of $\mathrm{GFAP}^{+}$astrocytes); the corresponding values in PBS-injected animals were $10.3 \%$ (microglia) and $8.5 \%$ (astrocytes). Neurons showed minimal IR for P2X $\mathrm{X}_{7} \mathrm{R}$ with respective values of $1 \%$ (LPS injection) and $0.7 \%$ (PBS injection). Thus, expression of $\mathrm{P} 2 \mathrm{X}_{7} \mathrm{R}$ is primarily upregulated in microglia and to a lesser extent in astrocytes in LPS-injected rat striatum.

\section{Effects of oxATP on LPS-mediated microglial activation}

We next examined the number of OX $-42^{+}$microglia and also morphological changes in the presence of oxATP, an inhibitor of $\mathrm{P} 2 \mathrm{X}_{7} \mathrm{R}$, injected intracerebroventricularly (at $1 \mu \mathrm{M}$ ) $30 \mathrm{~min}$ before LPS injection. Representative immunostaining for OX-42 is presented in Figure $2 A$ and shows that PBS injection (left panel) was mainly associated with a ramified morphology indicative of resting cells. LPS injection (at $5 \mu \mathrm{g}$ for $3 \mathrm{~d}$ ) induced an evident shift to an ameboid morphology with cells displaying roundish cell bodies and shortened processes (middle panel) suggestive of an activated state. Additionally, numbers of OX-42 ${ }^{+}$cells were increased in LPS-injected striatum. oxATP treatment (at $1 \mu \mathrm{M}$ ) was effective in diminishing the levels of OX- $42^{+}$microglia in LPS-injected striatum (right panel). oxATP alone did not induce morphological changes (data not shown).

OX-42-immunoreactive cells per square millimeter were counted for each treatment with overall results presented in Figure $2 \mathrm{~B}$. The numbers of microglia were almost tripled with LPS injection relative to PBS-injected striatum (140.7 \pm 4.1 and $51.2 \pm 2.0 / \mathrm{mm}^{2}$, respectively). In the presence of oxATP (at 1 $\mu \mathrm{M})$ with LPS, the corresponding numbers of OX- $42^{+}$cells were $92.3 \pm 3.3 / \mathrm{mm}^{2}(n=5$ animals $)$, representing a significant decrease (by $34.4 \%$ ) compared with LPS alone. These results suggest involvement of $\mathrm{P}_{2} \mathrm{X}_{7} \mathrm{R}$ in mediating LPS-induced microglial proliferative responses.

\section{Effects of oxATP on LPS-induced activation of p38 MAPK and NF $\mathrm{KB}$}

We then investigated the expression of p38 MAPK dependence on $\mathrm{P} 2 \mathrm{X}_{7} \mathrm{R}$ in LPS-injected striatum (at $5 \mu \mathrm{g}$ for $6,12,24$, and $72 \mathrm{~h}$ ) in the absence and presence of oxATP (at $1 \mu \mathrm{M}$ ) using double immunostaining. Little or no activation of p38 MAPK was observed in PBS-injected striatum (Fig. 3A, for $24 \mathrm{~h}$, top left). However, LPS injection ( $5 \mu \mathrm{g}$ for $24 \mathrm{~h}$ ) elicited a large degree of phosphorylation of p38 MAPK (green staining) in OX $-42^{+}$microglia (red staining) (top middle panel). The injection of oxATP effectively attenuated phosphorylation of p38 MAPK (right top panel).

The bar graph in Figure $3 B(n=4$ animals) shows the timedependent changes in p38 MAPK phosphorylation after LPS injection and subsequent inhibition in the presence of oxATP. Overall, at $24 \mathrm{~h}, 42.2 \pm 14.2$ cells $/ \mathrm{mm}^{2}$ expressed phosphorylated p38 MAPK in PBS-injected striatum. The corresponding values in LPS-injected and LPS plus oxATP-injected striatum were $184.5 \pm 17.4$ and $112.4 \pm 16.3$ cells $/ \mathrm{mm}^{2}$, respectively. The number of $38 \mathrm{MAPK}^{+}$cells was significantly decreased in the presence of oxATP by $39.1 \%$ compared with LPS alone. The corresponding decreases in $\mathrm{p} 38 \mathrm{MAPK}$ with oxATP at 12 and $72 \mathrm{~h}$ were 32.7 and $57.2 \%$, respectively; all effects were significant. These results suggest that activation of $\mathrm{P}_{2} \mathrm{X}_{7} \mathrm{R}$ is linked with downstream p38 MAPK activity in microglia.

The translocation of NF $\kappa \mathrm{B}$ to the nucleus initiates transcription of a number of proinflammatory mediators such as tumor necrosis factor- $\alpha$ (TNF- $\alpha$ ) (Combs et al., 2001). We next studied activation of NF $\kappa$ B in microglia with LPS stimulation (at $5 \mu \mathrm{g}$ for $6,12,24$, and $72 \mathrm{~h}$ ) in the absence and presence of oxATP. Representative immunostaining showed little activation of $\mathrm{NF} \kappa \mathrm{B}$ at $24 \mathrm{~h}$ in PBS-injected striatum (Fig. $3 A$, bottom left panel). Intrastriatal injection of LPS markedly upregulated nuclear translocation of the p65 subunit, a component of the NF $\kappa$ B p65/p50 heterodimer (bottom middle panel, green staining) localized with $\mathrm{OX}-42^{+}$microglia (red staining). The activation of $\mathrm{NF} \kappa \mathrm{B}$ was considerably reduced in the presence of oxATP (bottom right panel).

The bar graph in Figure $3 C$ ( $n=4$ animals) shows LPSinduced time-dependent changes in $\mathrm{NF} \kappa \mathrm{B}$ and inhibition in the presence of oxATP. Overall, at $24 \mathrm{~h}, 73.4 \pm 19.8 \mathrm{cells} / \mathrm{mm}^{2}$ expressed nuclear translocation of the p65 subunit in PBS-injected striatum. The corresponding values in LPS-injected and LPS plus oxATP-injected striatum were $403.2 \pm 42.1$ and $264.1 \pm 35.2$ cells $/ \mathrm{mm}^{2}$, respectively. The number of $\mathrm{p} 65^{+}$cells were significantly decreased in the presence of oxATP (by 34.5\%) compared with LPS alone. At the time points of 12 and $72 \mathrm{~h}$, oxATP reduced $\mathrm{NF} \kappa \mathrm{B}$ by 33.8 and $46.1 \%$, respectively, with both values reaching significance. Our results show that inhibition of $\mathrm{P} 2 \mathrm{X}_{7} \mathrm{R}$ attenuates LPS-induced activation of NF $\kappa \mathrm{B}$ in microglia. 
A

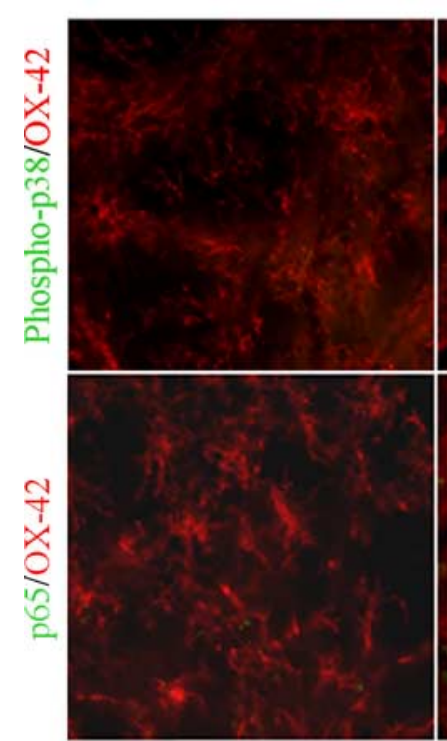

PBS
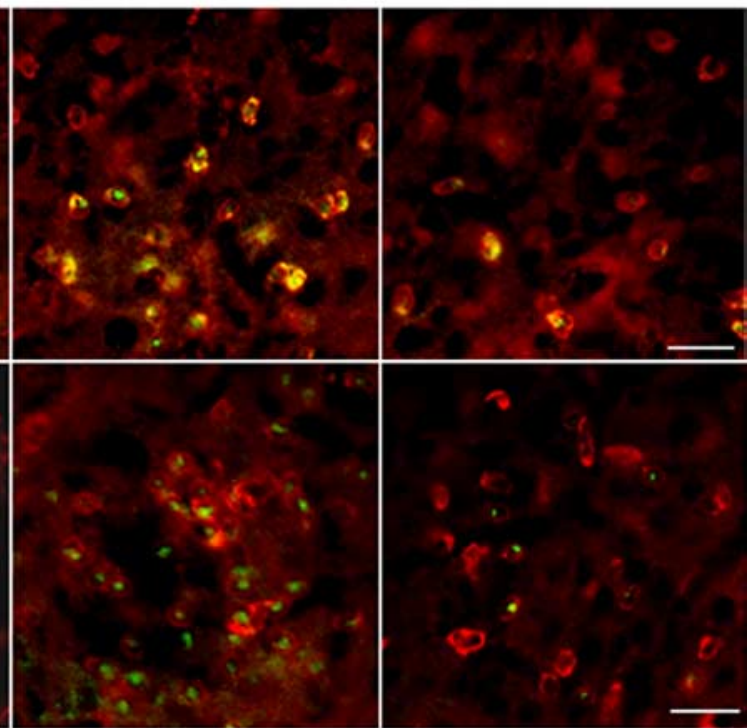

LPS

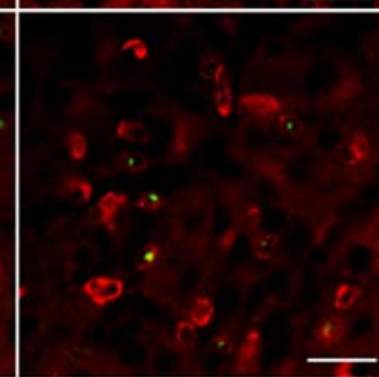

LPS + oxATP

\section{B}

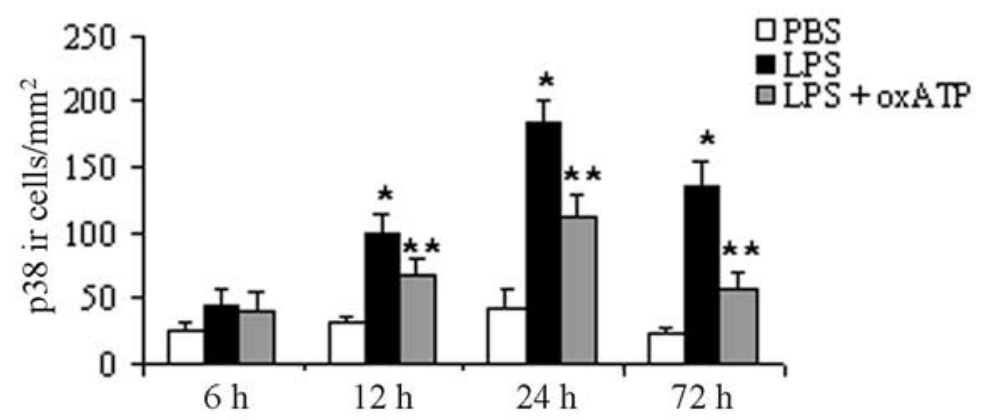

$\mathrm{C}$

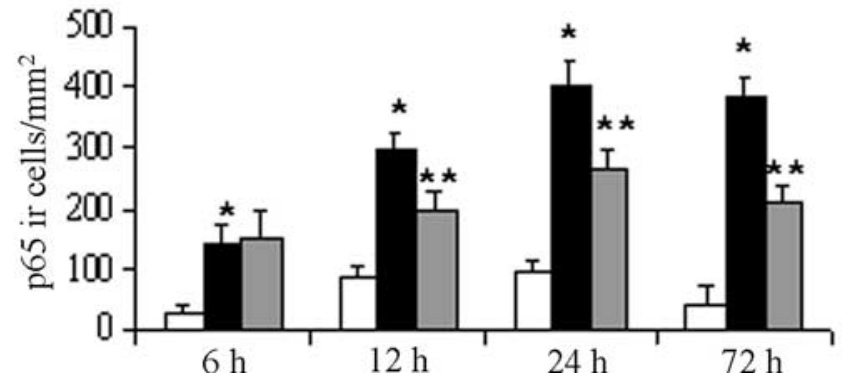

Figure 3. oxATP inhibits activation of $\mathrm{p} 38 \mathrm{MAPK}$ and NF $\kappa B$ ( $\mathrm{p} 65$ subunit) in LPS-injected rat striatum. $A$, Brain sections were double immunostained with phospho-p38 MAPK and 0X-42 antibodies $24 \mathrm{~h}$ after injection with PBS (top left), LPS (top middle), and LPS plus oxATP (top right). Brain sections were double immunostained with p65 and $0 X-42$ antibodies $24 \mathrm{~h}$ after injection with PBS (bottom left), LPS (bottom middle), and LPS plus oxATP (bottom right). Scale bars, $40 \mu \mathrm{m}$. B, The bar graph shows the time course of LPS-mediated p38 MAPK activation in the absence or presence of oxATP ( $n=4$ animals). $C$, The bar graph shows the time course of LPS-mediated p65 activation in the absence or presence of oxATP ( $n=4$ animals). ${ }^{*} p<0.05$ compared with PBSinjected group; ${ }^{* *} p<$ compared with LPS-injected group.

\section{Effects of oxATP on LPS-induced iNOS expression}

The involvement of $\mathrm{P} 2 \mathrm{X}_{7} \mathrm{R}$ in iNOS signaling was next investigated using RTPCR and immunohistochemical analysis. Production of iNOS was observed in a small population of cells in PBS-injected brain (Fig. $4 A$, left) but was considerably elevated with LPS injection $(5 \mu \mathrm{g}$ at $24 \mathrm{~h}$ after injection) (middle panel). The inset of Figure $4 \mathrm{~A}$ (middle) shows colocalization of iNOS (green) with OX- $42^{+}$microglia (red). In the presence of oxATP (at 1 $\mu \mathrm{M})$, LPS-induced production of iNOS was attenuated (right panel).

The time-dependent changes in numbers of iNOS ${ }^{+}$cells were measured at different time points $(6,12,24$, and $72 \mathrm{~h})$ with PBS injection or with LPS injection in the absence and presence of oxATP (at 1 $\mu \mathrm{M})$. As shown in Figure $4 B(n=4$ animals), little or no iNOS production was measured at any time point in PBSinjected rat brain. With LPS injection, the number of iNOS $^{+}$cells reached a maximum at $24 \mathrm{~h}$ and returned to a basal level at $72 \mathrm{~h}$ after injection. The numbers of iNOS $^{+}$cells were significantly reduced at $12 \mathrm{~h}(43.3 \%$ reduction $)$ and $24 \mathrm{~h}(56.3 \%$ reduction) in the presence of oxATP (at 1 $\mu \mathrm{M})$ compared with LPS alone.

RT-PCR was used to determine iNOS mRNA expression in PBS, LPS, and LPS plus oxATP-injected rat striatum. A representative RT-PCR result is presented in Figure $4 C$ (top), showing no expression of iNOS in PBS-injected rat striatum (lane 1, $12 \mathrm{~h}$ after injection). LPS ( $5 \mu \mathrm{g}, 12 \mathrm{~h}$ after injection) induced a high level of iNOS expression (lane 2) that was attenuated with oxATP treatment (lane 3). Semiquantification of RT-PCR results ( $n=3$ experiments) are presented in Figure $4 C$ (bottom). LPS injection induced a sixfold increase of iNOS expression relative to PBS-injected rat striatum, and LPS plus oxATP significantly reduced iNOS expression (by 67\%) from that measured with LPS alone. We conclude that inhibition of $\mathrm{P}_{2} \mathrm{X}_{7} \mathrm{R}$ reduces LPS-induced expression and production of iNOS in rat striatum.

\section{Effects of oxATP on}

\section{LPS-mediated nitration}

The enhancement of iNOS with LPS injection prompted us to examine the involvement of $\mathrm{P} 2 \mathrm{X}_{7} \mathrm{R}$ on LPS-induced nitration of proteins using 3-NT immunostaining. Representative immunostaining results (Fig. 5A) indicate that little or no $3-\mathrm{NT}^{+}$ cells were evident in PBS-injected control (top left panel). However, LPS injection (5 $\mu \mathrm{g}, 3 \mathrm{~d}$ after injection) increased the num- 
ber of $3-\mathrm{NT}^{+}$cells (top middle panel). In the presence of oxATP with LPS, the number of $3-\mathrm{NT}^{+}$cells was markedly attenuated (top right panel).

Double-staining immunofluorescence was then used to determine association of 3-NT with microglia. The results (Fig. 5A, bottom row) showed a high degree of colocalization of OX $-42^{+}$microglia with $3-\mathrm{NT}^{+}$cells in LPS-injected rat striatum (bottom middle panel). The presence of oxATP with LPS inhibited both OX-42 and 3-NT IR (bottom right panel).

The bar graph summarizing results is presented in Figure $5 B$ ( $n=5$ animals). Overall, a low level of $3-\mathrm{NT}^{+}$cells were colocalized with microglia in PBS-injected striatum $\left(1.1 \pm 0.6 / \mathrm{mm}^{2}\right.$ cells $)$. The corresponding values in LPS-injected and LPS plus oxATP-injected striatum were $40.1 \pm 4.8$ and $18.9 \pm 2.1 / \mathrm{mm}^{2}$ cells, respectively. The number of $3-\mathrm{NT}^{+}$cells was decreased in the presence of oxATP by 53\% compared with LPS alone. These findings suggest a role for $\mathrm{P}_{2} \mathrm{X}_{7} \mathrm{R}$ in microglia in mediating cellular production of peroxynitrite and oxidative stress in LPSinjected striatum.

We also examined extent of the colocalization of 3-NT with neurons. Representative double staining for 3-NT with striatal neurons (marker NeuN) is presented in Figure 5C. At $24 \mathrm{~h}$ after LPS injection, only a relatively small proportion of $\mathrm{NeuN}^{+}$cells appear associated with 3-NT. Examples of 3-NT with colocalization to neurons are indicated by arrows (Fig. $5 C$, middle). In the presence of oxATP, we estimate a twofold reduction in the number of 3-NT/NeuN cells.

\section{Effects of oxATP on LPS-mediated lipid peroxidation and oxidative \\ DNA damage}

Representative staining for effect of $\mathrm{P} 2 \mathrm{X}_{7} \mathrm{R}$ on LPS-induced lipid peroxidation (4HNE marker) in the rat striatum is shown (Fig. $6 A$, top row). LPS injection ( $5 \mu \mathrm{g}$ for $24 \mathrm{~h}$ ) induced extensive 4-HNE IR indicating lipid peroxidation in the striatum compared with PBS-injected striatum (Fig. 6A, top row). oxATP was effective in reducing the $4-\mathrm{HNE}^{+}$areas compared with LPS-injected striatum. Quantification in levels of 4-HNE is presented in Figure $6 B$, with LPS causing a considerable increase in 4-HNE IR (41-fold increase vs PBS). Treatment with oxATP was effective in reducing 4-HNE (by 50\% vs LPS alone; $n=5$ animals).

Reactive oxygen species can act on DNA, causing breakdown of DNA strands and base modification. $8-\mathrm{OHdG}$ is an ox-
A

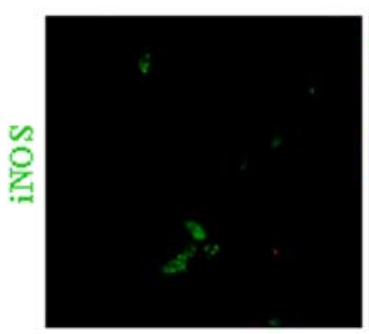

PBS

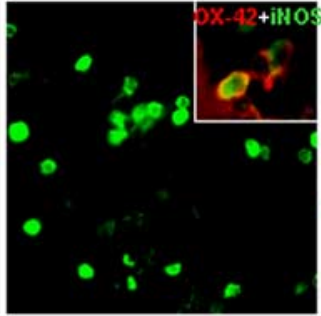

LPS

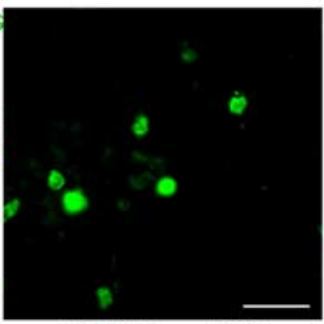

LPS + oxATP
B

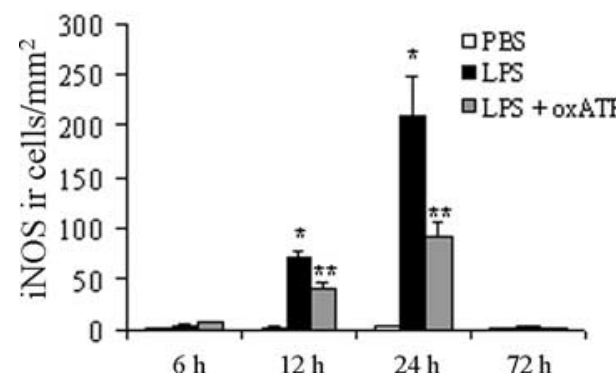

$\mathrm{C}$

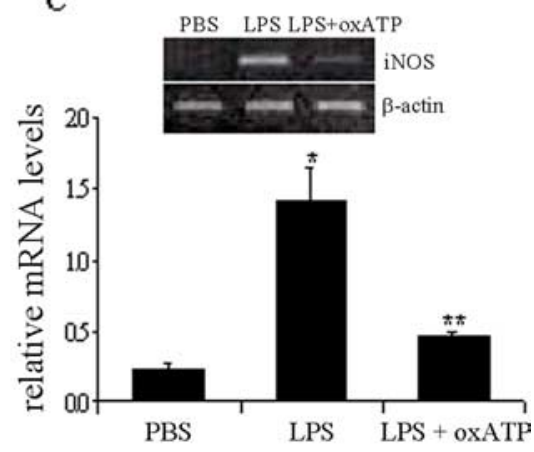

Figure 4. oxATP attenuates LPS-mediated iNOS expression in rat striatum. $A$, Brain tissues were immunostained with iNOS antibody after injection with PBS (left), LPS (middle), and LPS plus oxATP (right). LPS was injected ( $5 \mu \mathrm{g}$ for $24 \mathrm{~h}$ ) into rat striatum and oxATP (at $1 \mu \mathrm{m}$ ) was injected intracerebroventricularly $30 \mathrm{~min}$ before LPS injection. Scale bar, $30 \mu \mathrm{m}$. The inset in the middle shows colocalization of iNOS and $0 X-42{ }^{+}$microglia. $\boldsymbol{B}$, The bar graph shows the time course of iNOS expression, reaching maximum $24 \mathrm{~h}$ after LPS injection ( $n=4$ animals). C, Representative RT-PCR results for iNOS expression are presented from LPS-injected ( $12 \mathrm{~h}$ ) rat striatum; $\beta$-actin was used as a reaction standard. The bar graph shows semiquantitative RT-PCR results for expression of iNOS in rat striatum ( $n=3$ animals). ${ }^{*} p<0.05$ compared with PBS-injected group; ${ }^{* *} p<0.05$ compared with LPS-injected group.

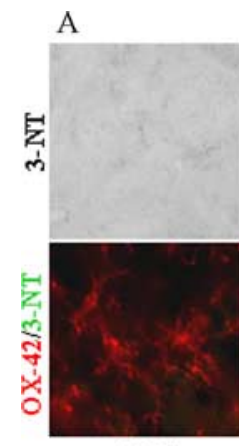

PBS

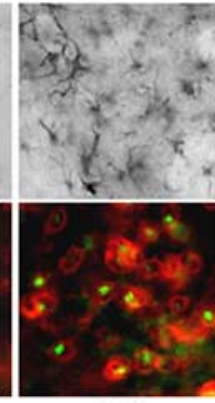

LPS

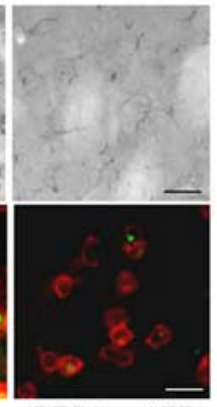

LPS + oxATP
B

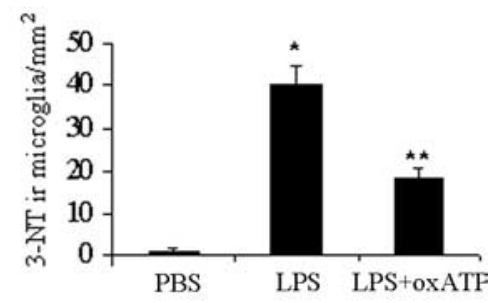

$\mathrm{C}$

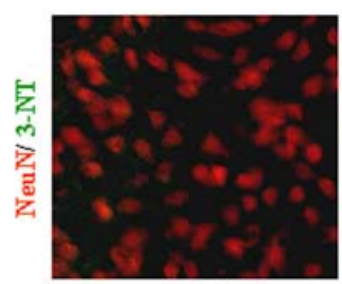

PBS

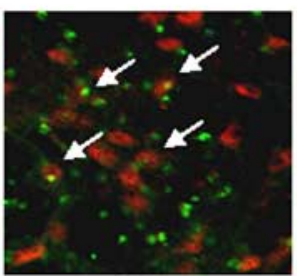

LPS

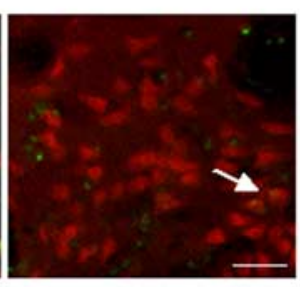

LPS+oxATP
Figure 5. oxATP reduces LPS-mediated nitration of proteins. $A$, Brain tissues were immunostained with 3-NT antibody $3 \mathrm{~d}$ after injection with PBS (top left), LPS (top middle), and LPS plus oxATP (top right). Brain sections were also double immunostained with 3-NT and OX-42 antibodies $3 \mathrm{~d}$ after injection with PBS (bottom left), LPS (bottom middle), and LPS plus oxATP (bottom right). Scale bars: top row, $40 \mu \mathrm{m}$; bottom row, $20 \mu \mathrm{m}$. $\boldsymbol{B}$, The bar graph shows effects of oxATP on LPS-mediated increase of 3-NT-immunoreactive microglia ( $n=5$ animals). C, Double staining for colocalization of 3-NT with NeuN ${ }^{+}$neurons (examples indicated by arrows) for the different treatments. Scale bar, $30 \mu \mathrm{m} .{ }^{*} p<0.05$ compared with PBS-injected group; ${ }^{* *} p<$ compared with LPS-injected group. 
A
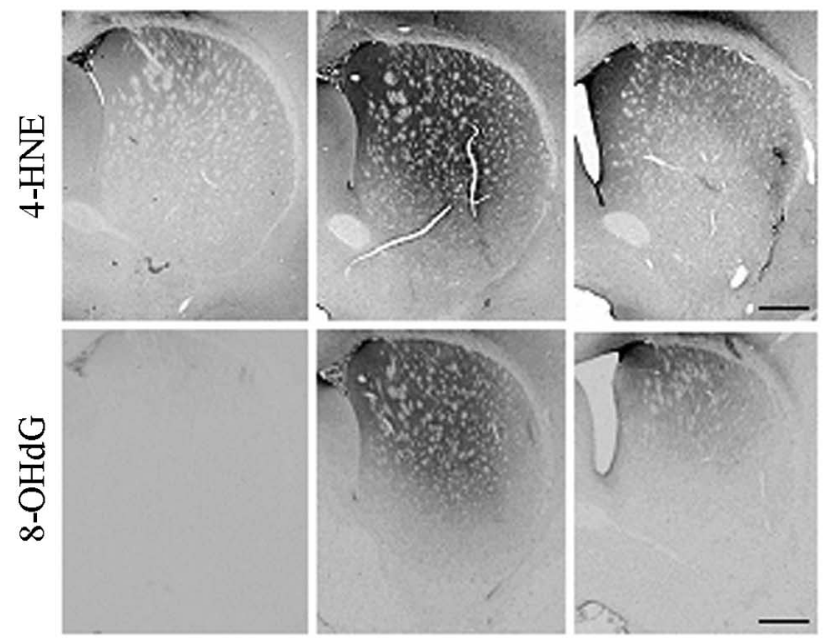

PBS

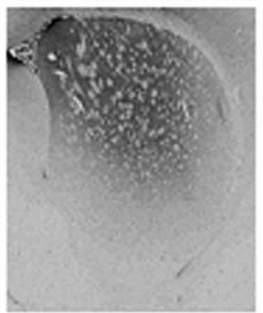

LPS

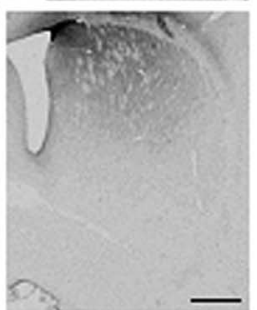

LPS + oxATP

B

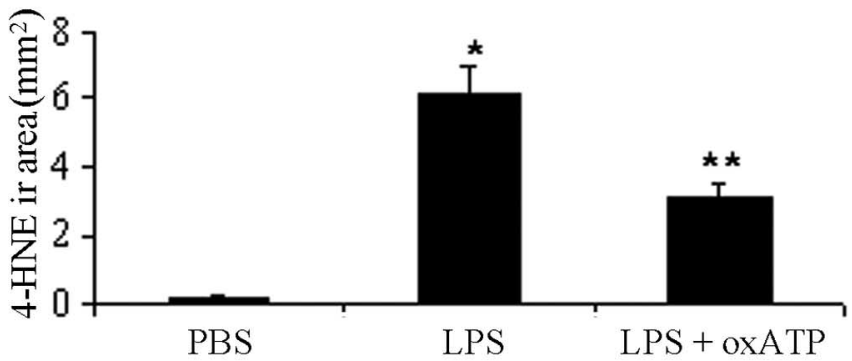

$\mathrm{C}$

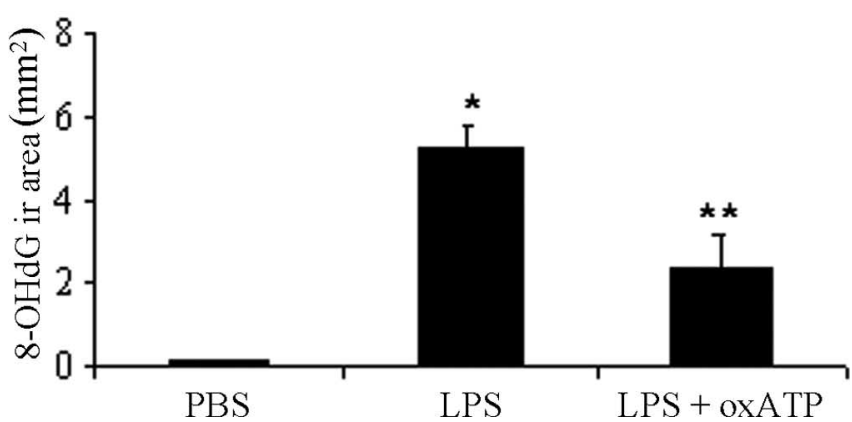

Figure 6. $\quad$ oxATP reduces LPS-induced lipid peroxidation and oxidative DNA damage. $\boldsymbol{A}$, Brain tissues were immunostained with 4-HNE antibody $24 \mathrm{~h}$ after injection with PBS (top left), LPS (top middle), and LPS plus oxATP (top right). Brain sections were immunostained with 8-0HdG antibody $24 \mathrm{~h}$ after injection with PBS (bottom left), LPS (bottom middle), and LPS plus 0xATP (bottom right). Scale bar, $1.0 \mathrm{~mm}$. Bar graphs show LPS stimulation of 4-HNE and 8-0HdG and effects of oxATP to block LPS-induced lipid peroxidation and oxidative DNA damage $(B, C$ respectively) ( $n=5$ animals). ${ }^{*} p<0.05$ compared with PBS-injected group; ${ }^{* *} p<$ compared with LPS-injected group.

idized form of deoxyguanosine, one of the constituents of DNA used as a marker for oxidative DNA damage (Kasai et al., 1987). Representative results are presented showing that LPS ( $5 \mu \mathrm{g}$ for $24 \mathrm{~h}$ ), but not PBS, injection was associated with 8-OHdG IR and oxidative DNA damage (Fig. $6 \mathrm{~A}$, bottom left and middle). In the presence of oxATP (at $1 \mu \mathrm{M}$ ), LPS-induced oxidative DNA damage was reduced (Fig. $6 \mathrm{~A}$, bottom right).

Quantification of data are presented in Figure 6C, with LPS injection eliciting a large increase in 8 -OHdG IR (52-fold increase vs PBS). LPS plus oxATP treatment significantly reduced $8-\mathrm{OHdG}^{+}$areas by $54 \%$ compared with LPS-injected striatum ( $n=5$ animals). Our results suggest that $\mathrm{P}_{2} \mathrm{X}_{7} \mathrm{R}$ is linked with oxidative stress and that oxATP inhibition of this purinergic subtype receptor reduces lipid peroxidation and oxidative DNA damage in LPS-injected rat striatum.

\section{Effects of oxATP on LPS-induced neuronal loss and caspase- 3 activation}

An important aspect of this work was to determine effects of $\mathrm{P} 2 \mathrm{X}_{7} \mathrm{R}$ modulation on extents of neuronal damage. We studied this point by measuring neuronal viability in LPS-injected striatum $(5 \mu \mathrm{g}$ for $3 \mathrm{~d})$ in the absence and presence of oxATP. Neuronal viability was assessed by counting immunostained neurons using NeuN antibody (Dou et al., 2003; Ryu et al., 2004). A typical result is shown in Figure $7 A$. The number of $\mathrm{NeuN}^{+}$cells was considerably decreased in LPS-injected striatum (Fig. 7A, middle panel) compared with PBS-injected control (left panel). However, in the presence of oxATP treatment, numbers of $\mathrm{NeuN}^{+}$ cells were increased (right panel) compared with LPS-injected striatum.

The overall results are shown in the bar graph in Figure $7 B$ ( $n=5$ animals). Numbers of $\mathrm{NeuN}^{+}$cells were counted in PBSinjected striatum and used as normalized control (100\%) to analyze neuronal viability. $\mathrm{NeuN}^{+}$cells were significantly decreased to $39.5 \pm 1.8 \%$ in LPS-injected striatum compared with PBS-injected striatum. However, oxATP pretreatment significantly increased numbers of striatal neurons to a level of $62 \%$, representing a significant degree of neuroprotection. Thus, activation of $\mathrm{P} 2 \mathrm{X}_{7} \mathrm{R}$ in microglia in inflammatory conditions is associated with enhancement of neuronal damage, an effect that is partially inhibited in the presence of oxATP.

We also investigated the effects of oxATP on LPS-mediated neuronal caspase- 3 activation at $24 \mathrm{~h}$ after LPS injection. Representative staining results for caspase-3 (green) and neurons (NeuN; red) are presented in Figure 7C. The results show little or no caspase-3 IR at $24 \mathrm{~h}$ in PBS-injected striatum (Fig. 7C, left panel) and elevated caspase- 3 in LPS-injected striatum (middle panel). Pretreatment with oxATP reduced caspase- 3 activation in LPS-injected brain (right panel). We examined caspase- 3 IR at different time points $(6,12,24$, and $72 \mathrm{~h})$ of LPS after injection and found a maximum caspase- 3 activation at $24 \mathrm{~h}$ with reduced levels at $72 \mathrm{~h}$ (data not shown).

The effects of oxATP on LPS-mediated neuronal caspase-3 activation are presented in Figure $7 D$. At $24 \mathrm{~h}$ after LPS injection, $18.1 \pm 3.4$ cells $/ \mathrm{mm}^{2}$ were caspase $-3^{+}$and oxATP at $1 \mu \mathrm{M}$ was effective in inhibiting ( $50 \%$ vs LPS alone) the activation of neuronal caspase- 3 ( $n=4$ animals). These results suggest that LPSinduced activation of $\mathrm{P} 2 \mathrm{X}_{7} \mathrm{R}$ in microglia may be involved in activation of neuronal caspase-3, leading to neuronal loss in LPSinjected animals.

\section{Effects of LPS intraperitoneal injection on expression of $\mathrm{P} 2 \mathrm{X}_{7} \mathrm{R}$}

An interesting question was whether application of peripheral LPS would also cause changes in striatal expression of $\mathrm{P} 2 \mathrm{X}_{7} \mathrm{R}$. This point was examined using intraperitoneal injection of the endotoxin (single intraperitoneal injections at 0.5 and $5 \mathrm{mg} / \mathrm{kg}$ ) with analysis for $\mathrm{P}_{2} \mathrm{X}_{7} \mathrm{R}$ expression at $24 \mathrm{~h}$ after intraperitoneal injection. Representative results are presented in Figure 8 and show no P2X $\mathrm{X}_{7} \mathrm{R}$ IR with control (PBS) administration (Fig. 8, left) and a small increase in the ionotropic receptor with the lower 
A

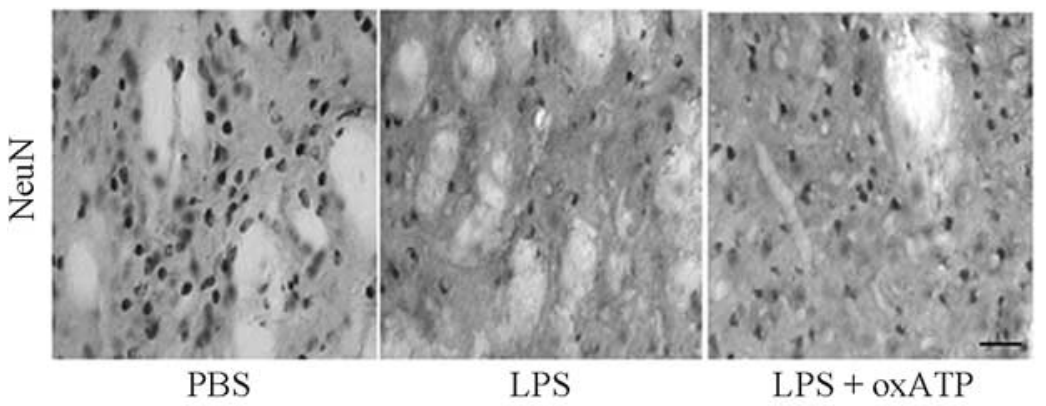

C

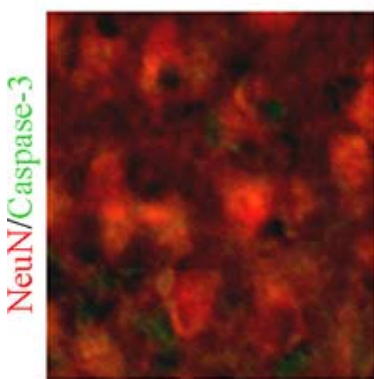

PBS

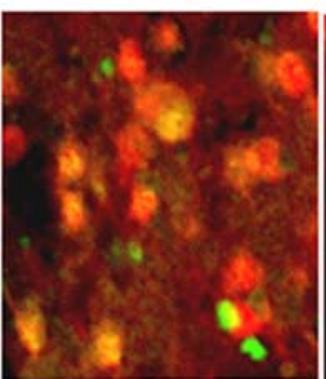

LPS

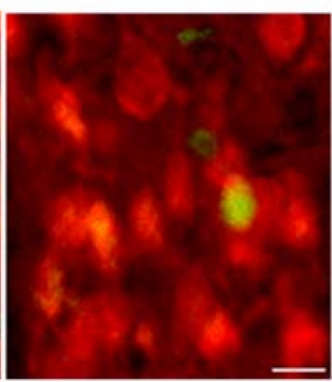

LPS + oxATP
B

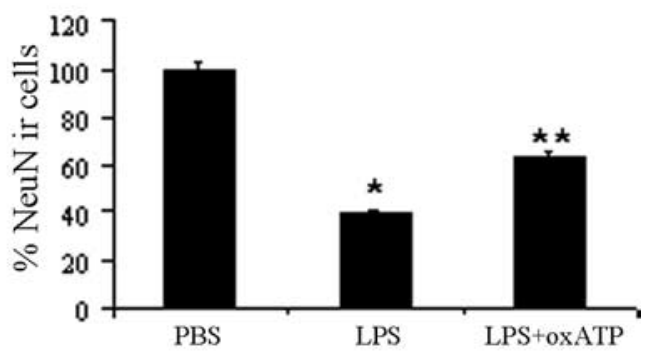

D

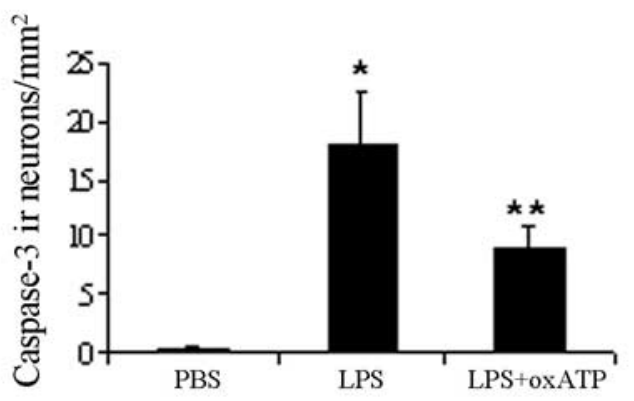

Figure 7. Immunostaining of brain sections with NeuN and caspase-3. $A$, Sections were immunostained with NeuN antibody $3 \mathrm{~d}$ after injection with PBS (left), LPS (middle), and LPS plus oxATP (right). Scale bar, $50 \mu \mathrm{m}$. B, The bar graph shows effects of oxATP on LPS-mediated decrease of NeuN IR ( $n=5$ animals). C, Brain sections were double immunostained with caspase-3 and NeuN antibodies $24 \mathrm{~h}$ after injection with PBS (left), LPS (middle), and LPS plus oxATP (right). NeuN ${ }^{+}$cells are presented in red, and caspase- 3 are shown in green. Scale bar, $15 \mu$ m. $\boldsymbol{D}$, The bar graph shows effects of oxATP on LPS-mediated (at $24 \mathrm{~h}$ ) increase of caspase-3-immunoreactive neurons ( $n=4$ animals). ${ }^{*} p<0.05$ compared with PBS-injected group; ${ }^{* *} p<$ compared with LPS-injected group.

dose of LPS $(0.5 \mathrm{mg} / \mathrm{kg}$, middle). At the higher LPS dose of $5 \mathrm{mg} / \mathrm{kg}$, a marked upregulation in $\mathrm{P} 2 \mathrm{X}_{7} \mathrm{R}$ expression was observed (right panel). These data are consistent with recent reports on effects of peripheral LPS to increase brain inflammation (see Discussion).

\section{Effects of oxATP on LPS-induced gene expressions in cultured \\ human microglia}

We examined the involvement of $\mathrm{P} 2 \mathrm{X}_{7} \mathrm{R}$ in LPS-induced gene expressions for proinflammatory and anti-inflammatory mediators and chemokines in human fetal microglia using RT-PCR. We first determined that exposure of cultured microglia to LPS $(100 \mathrm{ng} / \mathrm{ml})$ increased expression of $\mathrm{P} 2 \mathrm{X}_{7} \mathrm{R}$ in a timedependent manner (Fig. 9A). A low constitutive expression of receptor was detected in unstimulated microglia with maximum levels found at $8 \mathrm{~h}$ after LPS treatment. In the presence of oxATP (at $300 \mu \mathrm{M}$, applied $2 \mathrm{~h}$ before LPS treatment), LPS-induced upregulation of $\mathrm{P}_{2} \mathrm{X}_{7} \mathrm{R}$ was attenuated to near basal level (Fig. 9B).

Microglia were treated with LPS for $8 \mathrm{~h}$, in the absence and presence of oxATP (at $300 \mu \mathrm{M}$ ), to examine expressions of proinflammatory cytokines and inducible enzyme cyclooxygenase-2 (COX-2). A representative result is presented in Figure $9 C$. The results show no basal expressions of TNF- $\alpha$, IL-6, IL- $1 \beta$, IL-12, or COX-2 in control (Fig. 9C, lane 1). All inflammatory mediators were highly expressed after human microglia exposure to LPS (Fig. 9C, lane 2). LPS in the presence of oxATP abolished expres- sions of all factors (Fig. 9C, lane 3). oxATP treatment alone had no effect to alter expressions of the proinflammatory mediators (Fig. 9C, lane 4).

We next examined effects of LPS and oxATP on expression of the chemokines IL-8 and monocyte chemoattractant protein-1 (MCP-1) and the anti-inflammatory cytokines IL-10 and TGF$\beta 1$. LPS stimulation of human microglia induced expression of both chemokines, which were absent in unstimulated cells (Fig. 9D). oxATP treatment partially reduced expression of MCP-1 but not IL-8. Both TGF- $\beta 1$ and IL-10 were constitutively expressed in unstimulated microglia, and exposure to LPS did not alter the expression of these anti-inflammatory cytokines.

Semiquantitative RT-PCR results for proinflammatory and anti-inflammatory cytokines, enzyme COX-2, and the 
A

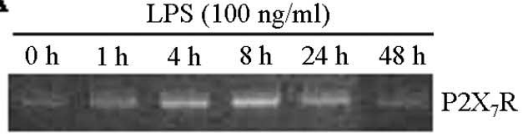

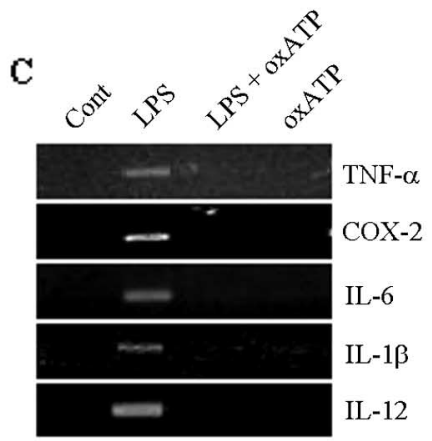

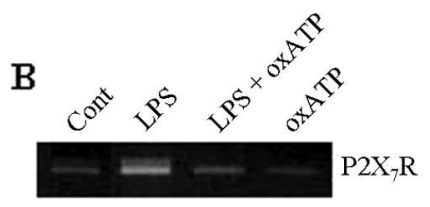

$\mathrm{D}$

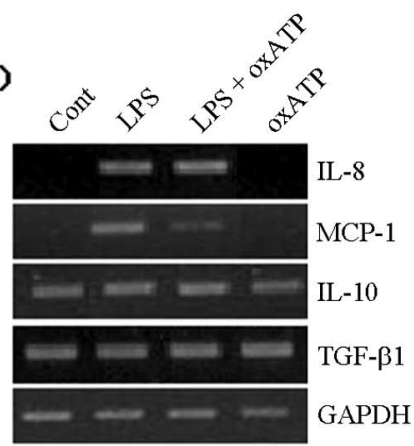

$\mathbf{E}$

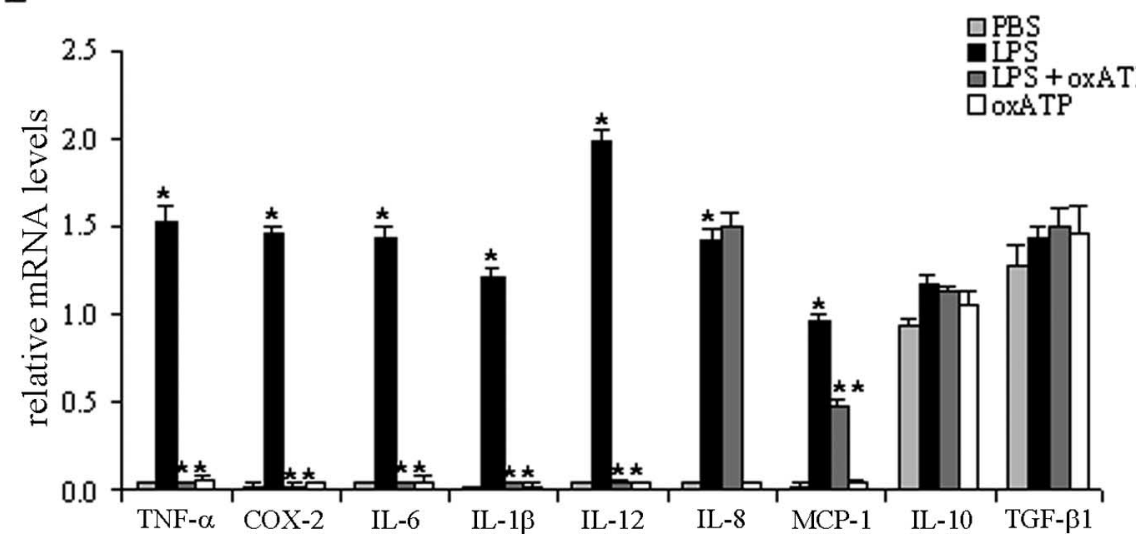

Figure 9. oxATP blocks LPS-induced proinflammatory mediators but not anti-inflammatory cytokines in cultured human microglia. $A$, The expressions of P2X $X_{7}$ were measured using RT-PCR; microglia were treated with LPS ( $100 \mathrm{ng} / \mathrm{ml}$ ) for different time points $(0,1,4,8,24$, and $48 \mathrm{~h})$. $B$, LPS (100 $\mathrm{ng} / \mathrm{ml}$ for $8 \mathrm{~h}$ ) induced upregulation of P2X $\mathrm{X}_{7}$ Rexpression which was inhibited by oxATP (at $300 \mu \mathrm{m}$, applied $2 \mathrm{~h}$ before LPS treatment). C, LPS (100 ng/ml for $8 \mathrm{~h}$ ) treatment induced upregulation of proinflammatory mediators, including TNF- $\alpha$, COX-2, IL-6, IL- $1 \beta$, and IL-12; all factors were inhibited by oxATP. D, LPS-induced expression of MCP-1, but not IL-8, was attenuated by oxATP. LPS did not alter expression of anti-inflammatory cytokines IL-10 and TGF- $\beta 1$. GAPDH was used as a reaction standard. $\boldsymbol{E}$, Semiquantitative RT-PCR results for proinflammatory mediators, chemokines, and anti-inflammatory cytokines are shown in the bar graph ( $n=3$ experiments). ${ }^{*} p<0.05$ compared with PBS-treated group; ${ }^{* *} p<$ compared with LPS-treated group.

chemokines are presented in the bar graphs in Figure $9 E(n=3$ experiments). oxATP was effective in reducing band intensities to below detectable levels for all proinflammatory mediators. Block of $\mathrm{P} 2 \mathrm{X}_{7} \mathrm{R}$ reduced LPS induction of MCP-1 expression by $50 \%$ with no effects on IL-8 or anti-inflammatory cytokines. The RTPCR results indicate that inhibition of $\mathrm{P} 2 \mathrm{X}_{7} \mathrm{R}$ using oxATP abolishes expression of proinflammatory cytokines and enzyme COX-2 and attenuates expression of MCP-1 in LPS-stimulated human microglia.

\section{Effects of oxATP on LPS-modulated $\left[\mathrm{Ca}^{2+}\right]_{\mathrm{i}}$ in cultured human microglia}

We initially measured effects of the selective $\mathrm{P} 2 \mathrm{X}_{7} \mathrm{R}$ agonist BzATP to mobilize $\left[\mathrm{Ca}^{2+}\right]_{i}$ in human microglia. BzATP (300 $\mu \mathrm{M}$ ) application (control, top trace) induced a prolonged $\left[\mathrm{Ca}^{2+}\right]_{\mathrm{i}}$ increase that was abolished with oxATP pretreatment (at $300 \mu \mathrm{M}$, applied $2 \mathrm{~h}$ before BzATP application) (Fig. 10 A, middle trace). In the absence of extracellular $\mathrm{Ca}^{2+}$, BzATP had no effect to alter
$\left[\mathrm{Ca}^{2+}\right]_{\mathrm{i}}$ (Fig. $10 \mathrm{~A}$, bottom trace). The importance of $\mathrm{Ca}^{2+}$ entry was also demonstrated using $\mathrm{Mn}^{2+}$ quenching experiments. As shown in Figure $10 \mathrm{~B}$, administration of BzATP in the presence of $\mathrm{Mn}^{2+}$ caused a rapid loss of fluorescence (measured at $360 \mathrm{~nm}$ ), indicating the nature of an influx pathway. The $\mathrm{Ca}^{2+}$ ionophore ionomycin elicited a small additional quenching of fluorescence.

Additional studies investigated possible interactions between BzATP and LPS in modulating mobilization of $\left[\mathrm{Ca}^{2+}\right]_{i}$ in human microglia. A typical sustained BzATP $(300 \mu \mathrm{M})$ response is presented in Figure 10C (labeled as control, middle trace). In the presence of LPS pretreatment $(100 \mathrm{ng} / \mathrm{ml}$ for $2 \mathrm{~h})$, the BzATPinduced increase in $\left[\mathrm{Ca}^{2+}\right]_{i}$ was considerably enhanced relative to control (Fig. $10 C$, top trace). The potentiation by LPS of the BzATP response was blocked by oxATP (at $300 \mu \mathrm{M}$ ) (Fig. 10C, bottom trace).

The bar graph summarizing results from experiments using procedures of Figure $10 C$ is presented in Figure $10 D$, showing a significant increase of peak amplitudes (by $274 \%$ ) of $\left[\mathrm{Ca}^{2+}\right]_{i}$ with LPS pretreatment compared with BzATP response in the absence of LPS ( $n=5$ separate experiments). BzATP-induced enhancement of $\left[\mathrm{Ca}^{2+}\right]_{\mathrm{i}}$ in the presence of LPS (100 ng/ml for $2 \mathrm{~h}$ ) was reduced with pretreatment of oxATP (by 89\%). These results suggest that LPS potentiation of $\mathrm{P} 2 \mathrm{X}_{7} \mathrm{R}$-mediated $\left[\mathrm{Ca}^{2+}\right]_{\mathrm{i}}$ mobilization may lead to modulation of functional responses in human microglia.

\section{Discussion}

An important finding from this work is that activation of $\mathrm{P}_{2} \mathrm{X}_{7} \mathrm{R}$ in LPS-injected rat striatum is intimately linked with enhancement of a spectrum of inflammatory processes and a significant loss in numbers of striatal neurons. Most importantly, oxATP inhibition of $\mathrm{P}_{2} \mathrm{X}_{7} \mathrm{R}$ was effective in the inhibition of LPSinduced inflammation and was neuroprotective in inflamed brains. As discussed below, the overall results from in vivo and in vitro studies implicate $\mathrm{P} 2 \mathrm{X}_{7} \mathrm{R}$ in microglia as a critical factor in mediating inflammatory responses.

Double-immunofluorescence-staining measurements showed $\mathrm{P} 2 \mathrm{X}_{7} \mathrm{R}$ to be primarily associated with microglia, with a considerably smaller proportion of purinergic receptors colocalized with astrocytes; $\mathrm{NeuN}^{+}$cells showed no expression of P2 $\mathrm{X}_{7} \mathrm{R}$ (Fig. 1). Previous work has documented expression of $\mathrm{P} 2 \mathrm{X}_{7} \mathrm{R}$ in glia (Collo et al., 1997), with some reports for the presence of this purinergic receptor subtype in neurons (Deuchars et al., 2001; Franke et al., 2004). Immunostaining patterns for OX$42^{+}$microglia (Fig. 2A) indicated a predominantly ramified morphology for PBS injection, with cells showing small bodies and fine processes. In contrast, LPS intrastriatal injection was associated with ameboid morphology, with cells exhibiting 
A

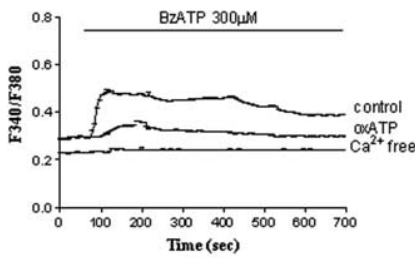

$\mathrm{C}$

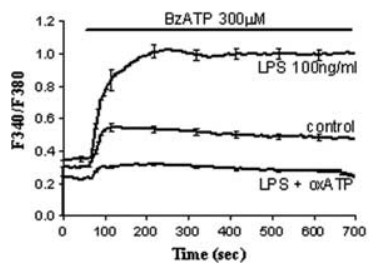

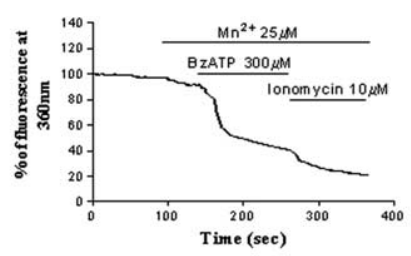

D

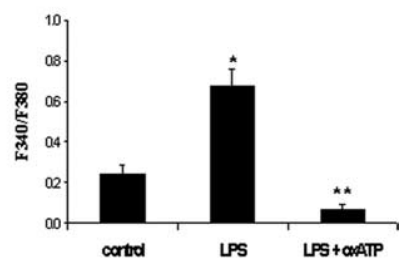

Figure 10. LPS pretreatment modulates $P 2 X_{7} R$-mediated $\left[\mathrm{Ca}^{2+}\right]_{i}$ mobilization in cultured human microglia. A, BzATP (at $300 \mu \mathrm{m}$ ) induced a prolonged $\left[\mathrm{Ca}^{2+}\right]_{i}$ increase (top trace; $n=$ 22 cells) with block by oxATP pretreatment (at $300 \mu \mathrm{m}$, applied $2 \mathrm{~h}$ before LPS treatment, $n=$ 16 cells; middle trace). BzATP induced a minimal increase of $\left[\mathrm{Ca}^{2+}\right]_{i}$ in the absence of extracelIular $\mathrm{Ca}^{2+}$ ( $n=23$ cells; bottom trace). $\boldsymbol{B}, \mathrm{Mn}^{2+}$ quenching in $\mathrm{Ca}^{2+}$-free solution shows that BzATP application was associated with a significant decrease in fluorescence indicative of $\mathrm{Mn}^{2+}$ influx in human microglia ( $n=20$ cells). C, LPS (for $2 \mathrm{~h}$ at $100 \mathrm{ng} / \mathrm{ml}, n=28$ cells; top trace) pretreatment significantly enhanced BzATP to increase $\left[\mathrm{Ca}^{2+}\right]_{i}$ compared with control (cells with no LPS exposure, $n=25$ cells; middle trace). oxATP (at $300 \mu \mathrm{m}, n=33$ cells; bottom trace) preincubation inhibited LPS potentiation of $\left[\mathrm{Ca}^{2+}\right]_{i}$ induced by BzATP. $D$, The bar graph shows LPS potentiation of BzATP to increase $\left[\mathrm{Ca}^{2+}\right]_{i}$, an effect that was inhibited by oxATP. Five independent experiments performed for all calcium experiments. ${ }^{*} p<0.05$ compared with control group (no exposure to LPS); ${ }^{* *} p<$ compared with LPS pretreated group.

swollen cell bodies and retracted processes (Fig. 2B). oxATP treatment before LPS injection was highly effective in reducing numbers of activated microglia, but remaining $\mathrm{OX}-42^{+}$cells still showed an ameboid morphology (Fig. 2C). This result would suggest that, although oxATP reduced the number of activated microglia, the $\mathrm{P}_{2} \mathrm{X}_{7} \mathrm{R}$ antagonist did not prevent cellular activation. Supranigral LPS administration has been reported to increase numbers of OX $-42^{+}$microglia and to induce a shift in morphology from resting to activated state (measured at $24 \mathrm{~h}$ after LPS injection) (Iravani et al., 2005). At a longer time of $30 \mathrm{~d}$ after LPS injection, numbers of OX $-42^{+}$microglia were then reduced, with cells showing a predominant ramified morphology.

LPS induced similar patterns of time-dependent changes in the intracellular signaling pathway p38 MAPK and the nuclear transcription factor $\mathrm{NF} \kappa \mathrm{B}$ in microglia (Fig. 3). Treatment with oxATP effectively reduced IR for both p 38 MAPK and NF $\kappa$ B for all but the earliest time point of $6 \mathrm{~h}$ after LPS injection. The similarity in time-dependent changes and pharmacological actions of oxATP indicate coupling between the two intracellular inflammatory mediators. Our results suggest that p38 MAPK and $\mathrm{NF} \kappa \mathrm{B}$ regulate a proliferative microglial response rather than cellular activation. Proliferation of microglia has been associated with phosphorylation of p38 MAPK (Tikka et al., 2001) and activation of NF $\kappa$ B (Ryu et al., 2002; Suo et al., 2003).

Because nitrogen species contribute to responses in inflamed brain (Brown and Bal-Price, 2003; Lee et al., 2005), we examined levels of inducible enzyme iNOS and 3-NT. Marked upregulation of iNOS was evident in LPS-injected striatum (at $24 \mathrm{~h}$ ) with colocalization to microglia (Fig. 4); expression of the enzyme was significantly reduced with oxATP. RT-PCR results (at $12 \mathrm{~h}$ after LPS injection) also indicated upregulation of iNOS relative to

control (PBS injection). Double-immunofluorescence staining, performed at the time of maximum iNOS response $(24 \mathrm{~h}$ after LPS injection), indicated colocalization of 3-NT with OX-42 ${ }^{+}$ microglia (Fig. 5A). The expressions of 3-NT and OX-42 were attenuated by oxATP. Evidence for colocalization of 3-NT with neurons was found (Fig. 5C) but comprised a minority of the neuronal population. In the presence of oxATP, we estimate a twofold reduction in the number of 3-NT/NeuN cells.

Previous work has reported involvement of 3-NT in LPSinduced brain damage (Tomas-Camardiel et al., 2004) and effects of oxATP to downregulate iNOS expression and nitric oxide production in LPS-primed macrophages (Hu et al., 1998). The inhibition of iNOS has a reported neuroprotective effect in an animal model of LPS-mediated inflammation (Arimoto and Bing, 2003). Recent work has also reported that glial-derived nitrogen species mediate enhanced blood-brain barrier permeability in amyloid$\beta$-injected rat hippocampus (Ryu and McLarnon, 2006).

The effect of oxATP to inhibit lipid peroxidation is a novel finding in this study. Both oxidative stress markers 4-HNE and 8-OHdG were absent in PBS-injected striatum, considerably elevated with LPS injection, and reduced with oxATP pretreatment of LPS-injected striatum (Fig. 6). In the latter case, similar effects of oxATP to block 4-HNE (by 56\%) and 8-OHdG (by 60\%), relative to LPS alone, were found. Inhibition of oxidative stress may be linked with effects on neuronal viability. Double immunostaining (NeuN/caspase-3) showed upregulation of neuronal caspase- 3 in LPS-injected striatum with suppression by oxATP. To translate caspase- 3 activity to neuronal viability, numbers of $\mathrm{NeuN}^{+}$striatal neurons were counted. At $3 \mathrm{~d}$ after LPS injection, numbers of neurons were reduced relative to PBS with partial recovery for oxATP pretreatment before LPS application. The involvement of caspase-3 in neuronal damage (Fig. 7) is consistent with findings of upregulation of this factor in LPS-injected (Cunningham et al., 2005) and quinolinic acid-injected (Ryu et al., 2005) rat brain. In the latter study, pharmacological inhibition of microglial activation reduced neuronal caspase- 3 activation and was neuroprotective.

An ancillary question addressed in this work was the effect of application of peripheral LPS on striatal $\mathrm{P}_{2} \mathrm{X}_{7} \mathrm{R}$. The results (Fig. 8 ) showed that both low and high intraperitoneal injections of LPS $\left(0.5\right.$ and $5 \mathrm{mg} / \mathrm{kg}$ ) induced an increased P2X $\mathrm{X}_{7} \mathrm{R}$ expression relative to PBS control. Although results were not quantified, the higher dose of LPS yielded marked increases in levels of the purinergic ionotropic receptor. These data are consistent with recent reports on actions of peripheral LPS to induce inflammatory responses in brain. In one study (Qin et al., 2007), a single systemic dose of LPS ( $5 \mathrm{mg} / \mathrm{kg}$, i.p.) caused a sustained increase in brain levels of the inflammatory factors TNF- $\alpha$, IL-1 $\beta$, MCP-1, and $\mathrm{NF} \kappa \mathrm{B}$ p 65 and also damage to dopaminergic neurons. The authors suggested that LPS effects were attributable to actions of TNF- $\alpha$ to transfer information from periphery to brain. Effects of intraperitoneal injection of LPS on inflammation in wild-type and prion disease mice have been examined (Cunningham et al., 2005). The results showed increased levels of proinflammatory cytokines and other inflammatory factors in both groups of animals compared with controls, with diseased mice showing enhanced inflammation relative to wild-type animals.

Results from in vitro experiments supported in vivo findings and suggested a novel mechanism underlying inflammatory responses. LPS induced significant $\mathrm{P} 2 \mathrm{X}_{7} \mathrm{R}$ expression in human microglia with partial block by oxATP (Fig. 9B), indicating that oxATP interferes with a signal to increase mRNA. LPS stimulation of microglia elevated expressions of proinflammatory fac- 
tors (COX-2, TNF- $\alpha$, IL-6, IL-1 $\beta$, and IL-12); all factors were inhibited by oxATP pretreatment. Expressions of the chemokines IL- 8 and MCP- 1 were also increased in stimulated cells, but only MCP-1 was sensitive to oxATP. Interestingly, LPS stimulation had no effect to alter expressions of the anti-inflammatory cytokines IL- 10 and TGF- $\beta 1$. Thus, activation of $\mathrm{P} 2 \mathrm{X}_{7} \mathrm{R}$ in microglia leads to enhanced cellular expression of an assemblage of proinflammatory mediators that, cumulatively, cause neuronal damage.

A putative mechanism to account for $\mathrm{P}_{2} \mathrm{X}_{7} \mathrm{R}$-dependent inflammatory processes is LPS amplification of the entry of $\mathrm{Ca}^{2+}$ through the associated pore. Stimulation of human microglia with the specific $\mathrm{P} 2 \mathrm{X}_{7} \mathrm{R}$ ligand BzATP caused a sustained increase in $\left[\mathrm{Ca}^{2+}\right]_{\mathrm{i}}$ that was blocked by oxATP and abolished in $\mathrm{Ca}^{2+}$-free PSS. A novel finding, however, was that LPS pretreatment was highly effective in the potentiation of $\left[\mathrm{Ca}^{2+}\right]_{i}$ induced by BzATP (Fig. 10C,D). This result would be consistent with direct LPS enhancement in numbers of $\mathrm{P}_{2} \mathrm{X}_{7} \mathrm{R}$. Another possibility is that LPS stimulated microglial release of ATP, which then activated additional ${\mathrm{P} 2 X_{7}}_{7}$ receptors (Ferrari et al., 1997). In any event, relatively high levels of ATP (in excess of $1 \mathrm{~mm}$ ) seem generally required to activate $\mathrm{P} 2 \mathrm{X}_{7} \mathrm{R}$ (Hide et al., 2000; McLarnon, 2005). Such elevated concentrations of ATP could be expected under pathological situations whereby endogenous cells were damaged and chronically leaky. However, to our knowledge, no evidence for such high levels of ATP have been reported in brain. In this case, the measurement of transient localized ATP may be confounded by the rapid enzymatic activity of nucleotidases. It is also possible that lower concentrations of ATP may be effective in activating $\mathrm{P}_{2} \mathrm{X}_{7} \mathrm{R}$ in vivo.

An important consideration is the possible limitation in the use of oxATP as a selective $\mathrm{P} \mathrm{X}_{7} \mathrm{R}$ antagonist. Although oxATP has often been characterized in this manner, other work has reported nonselectivity in actions of this compound. In a study of three different cell types not expressing P2 $\mathrm{X}_{7} \mathrm{R}$, oxATP was effective in attenuating LPS induction of inflammatory mediators (Beigi et al., 2003). Furthermore, this work also reported oxATP inhibitory actions against LPS-induced nitric oxide production when applied to $\mathrm{P}_{2} \mathrm{X}_{7} \mathrm{R}$ knock-out mice. Thus, oxATP could act to inhibit proinflammatory responses in a manner independent of effects on $\mathrm{P} 2 \mathrm{X}_{7} \mathrm{R}$.

In conclusion, the present work has documented functional roles for $\mathrm{P} 2 \mathrm{X}_{7} \mathrm{R}$ in inducing inflammatory responses in an animal model of inflamed brain. Supporting evidence for LPS-induced potentiation of $\mathrm{Ca}^{2+}$ influx through this purinergic receptor subtype has been derived from in vitro study. Importantly, inhibition of $\mathrm{P} 2 \mathrm{X}_{7} \mathrm{R}$-mediated signaling by oxATP has been found effective in limiting inflammatory responses and conferring neuroprotection. Overall, our results suggest modulation of $\mathrm{P}_{2} \mathrm{X}_{7} \mathrm{R}$ as a plausible strategy for therapeutic intervention to reduce the damaging effects of inflammation in neurodegenerative diseases.

\section{References}

Arimoto T, Bing G (2003) Upregulation of inducible nitric oxide synthase in the substantia nigra by lipopolysaccharide causes microglial activation and neurodegeneration. Neurobiol Dis 12:35-45.

Ayata C, Ayata G, Hara H, Matthews RT, Beal MF, Ferrante RJ, Endres M, Kim A, Christie RH, Waeber C, Huang PL, Hyman BT, Moskowitz MA (1997) Mechanisms of reduced striatal NMDA citotoxicity in type I nitric oxide synthase knock-out mice. J Neurosci 17:6908-6917.

Beigi RD, Kertesy SB, Aquilina G, Dubyak GR (2003) Oxidized ATP (oATP) attenuates proinflammatory signaling via P2 receptor-independent mechanisms. Br J Pharmacol 140:507-519.

Brown GC, Bal-Price A (2003) Inflammatory neurodegeneration mediated by nitric oxide, glutamate, and mitochondria. Mol Neurobiol 27:325-355.

Collo G, Neidhart S, Kawashima E, Kosco-Vilbois M, North RA, Buell G (1997) Tissue distribution of the P2X7 receptor. Neuropharmacology 36:1277-1283.

Combs CK, Karlo JC, Kao SC, Landreth GE (2001) $\beta$-Amyloid stimulation of microglia and monocytes results in TNF $\alpha$-dependent expression of inducible nitric oxide synthase and neuronal apoptosis. J Neurosci 21:1179-1188.

Cunningham C, Wilcockson DC, Campion S, Lunnon K, Perry VH (2005) Central and systemic endotoxin challenges exacerbate the local inflammatory response and increase neuronal death during chronic neurodegeneration. J Neurosci 25:9275-9284.

Deuchars SA, Atkinson L, Brooke RE, Musa H, Milligan CJ, Batten TF, Buckley NJ, Parson SH, Deuchars J (2001) Neuronal P2X7 receptors are targeted to presynaptic terminals in the central and peripheral nervous systems. J Neurosci 21:7143-7152.

Dou H, Birusingh K, Faraci J, Gorantla S, Poluektova LY, Maggirwar SB, Dewhurst S, Gelbard HA, Gendelman HE (2003) Neuroprotective activities of sodium valproate in a murine model of human immunodeficiency virus-1 encephalitis. J Neurosci 23:9162-9170.

Ferrari D, Chiozzi P, Falzoni S, Dal Susino M, Collo G, Buell G, Di Virgilio F (1997) ATP-mediated cytotoxicity in microglial cells. Neuropharmacology 36:1295-1301.

Ferrari D, Los M, Bauer MK, Vandenabeele P, Wesselborg S, Schulze-Osthoff K (1999) P2Z purinoreceptor ligation induces activation of caspases with distinct roles in apoptotic and necrotic alterations of cell death. FEBS Lett 447:71-75.

Ferrari CC, Pott Godoy MC, Tarelli R, Chertoff M, Depino AM, Pitossi FJ (2006) Progressive neurodegeneration and motor disabilities induced by chronic expression of IL-1beta in the substantia nigra. Neurobiol Dis 24:183-193.

Franke H, Gunther A, Grosche J, Schmidt R, Rossner S, Reinhardt R, FaberZuschratter H, Schneider D, Illes P (2004) P2X 7 receptor expression after ischemia in the cerebral cortex of rats. J Neuropathol Exp Neurol 63:686-699.

Griffin WS, Mrak RE (2002) Interleukin-1 in the genesis and progression of and risk for development of neuronal degeneration in Alzheimer's disease. J Leukoc Biol 72:233-238.

Gudipaty L, Munetz J, Verhoef PA, Dubyak GR (2003) Essential role for $\mathrm{Ca}^{2+}$ in regulation of IL-1beta secretion by P2X7 nucleotide receptor in monocytes, macrophages, and HEK-293 cells. Am J Physiol Cell Physiol 285:C286-C299.

Hide I, Tanaka M, Inoue A, Nakajima K, Kohsaka S, Inoue K, Nakata Y (2000) Extracellular ATP triggers tumor necrosis factor-alpha release from rat microglia. J Neurochem 75:965-972.

Hu Y, Fisette PL, Denlinger LC, Guadarrama AG, Sommer JA, Proctor RA, Bertics PJ (1998) Purinergic receptor modulation of lipopolysaccharide signaling and inducible nitric-oxide synthase expression in RAW 264.7 macrophages. J Biol Chem 273:27170-27175.

Humphreys B, Rice J, Kertesy S, Dubyak G (2000) SAPK/JNK activation and apoptotic induction by the macrophage P2X7 nucleotide receptor. J Biol Chem 275:26792-26798.

Iravani MM, Leung CC, Sadeghian M, Haddon CO, Rose S, Jenner P (2005) The acute and the long-term effects of nigral lipopolysaccharide administration on dopaminergic dysfunction and glial cell activation. Eur J Neurosci 22:317-330.

Kasai H, Nishimura S, Kurokawa Y, Hayashi Y (1987) Oral administration of the renal carcinogen, potassium bromate, specifically produces 8-hydroxydeoxyguanosine in rat target organ DNA. Carcinogenesis 8:1959-1961.

Khoo C, Helm J, Choi HB, Kim SU, McLarnon JG (2001) Inhibition of store-operated $\mathrm{Ca}^{2+}$ influx by acidic extracellular $\mathrm{pH}$ in cultured human microglia. Glia 36:22-30.

Klegeris A, McGeer PL (2005) Non-steroidal anti-inflammatory drugs (NSAIDs) and other anti-inflammatory agents in the treatment of neurodegenerative disease. Curr Alzheimer Res 2:355-365.

Lee JC, Cho GS, Kim HJ, Lim JH, Oh YK, Nam W, Chung JH, Kim WK (2005) Accelerated cerebral ischemic injury by activated macrophages/ microglia after lipopolysaccharide microinjection into rat corpus callosum. Glia 50:168-181.

Le Feuvre RA, Brough D, Iwakura Y, Takeda K, Rothwell NJ (2002) Priming 
of macrophages with lipopolysaccharide potentiates P2X7-mediated cell death via a caspase-1-dependent mechanism, independently of cytokine production. J Biol Chem 277:3210-3218.

Li Y, Liu L, Barger SW, Griffin WS (2003) Interleukin-1 mediates pathological effects of microglia on tau phosphorylation and on synaptophysin synthesis in cortical neurons through a p38-MAPK pathway. J Neurosci 23:1605-1611.

Lue LF, Rydel R, Brigham EF, Yang L, Hampel H, Murphy GM, Brachova L, Yan SD, Walker DG, Rogers J (2001) Inflammatory repertoire of Alzheimer's disease and nondemented elderly microglia in vitro. Glia 35:72-79.

McGeer PL, McGeer EG (1998) Glial cell reactions in neurodegenerative diseases: pathophysiology and therapeutic interventions. Alzheimer Dis Assoc Disord 12 [Suppl 2]:S1-S6.

McLarnon JG (2005) Purinergic mediated changes in $\mathrm{Ca}^{2+}$ mobilization and functional responses in microglia: effects of low levels of ATP. J Neurosci Res 81:349-356.

McLarnon JG, Franciosi S, Wang X, Bae JH, Choi HB, Kim SU (2001) Acute actions of tumor necrosis factor-alpha on intracellular $\mathrm{Ca}^{2+}$ and $\mathrm{K}^{+}$ currents in human microglia. Neuroscience 104:1175-1184.

Moller T (2002) Calcium signaling in microglial cells. Glia 40:184-194.

Nagai A, Nakagawa E, Hatori K, Choi HB, McLarnon JG, Lee MA, Kim SU (2001) Generation and characterization of immortalized human microglial cell lines: expression of cytokines and chemokines. Neurobiol Dis 8:1057-1068.

Parvathenani LK, Tertyshnikova S, Greco CR, Roberts SB, Robertson B, Posmantur R (2003) P2X7 mediates superoxide production in primary microglia and is upregulated in a transgenic mouse model of Alzheimer's disease. J Biol Chem 278:13309-13317.

Paxinos G, Watson C (1998) The rat brain in stereotaxic coordinates, Ed 4. San Diego: Academic.

Qin L, Wu X, Block ML, Liu Y, Breese GR, Hong JS, Knapp DJ, Crews FT (2007) Systemic LPS causes chronic neuroinflammation and progressive neurodegeneration. Glia 55:453-462.

Rampe D, Wang L, Ringheim GE (2004) P2X7 receptor modulation of betaamyloid- and LPS-induced cytokine secretion from human macrophages and microglia. J Neuroimmunol 147:56-61.

Rothwell NJ, Luheshi GN (2000) Interleukin 1 in the brain: biology, pathology and therapeutic target. Trends Neurosci 23:618-625.

Ryu JK, McLarnon JG (2006) Minocycline or iNOS inhibition block 3-nitrotyrosine increases and blood-brain barrier leakiness in amyloid beta-peptide-injected rat hippocampus. Exp Neurol 198:552-557.

Ryu J, Min KJ, Rhim TY, Kim TH, Pyo H, Jin B, Kim SU, Jou I, Kim SS, Joe EH (2002) Prothrombin kringle-2 activates cultured rat brain microglia. J Immunol 168:5805-5810.

Ryu JK, Nagai A, Kim J, Lee MC, McLarnon JG, Kim SU (2003) Microglial activation and cell death induced by the mitochondrial toxin 3 -nitropropionic acid: in vitro and in vivo studies. Neurobiol Dis 12:121-132.

Ryu JK, Kim SU, McLarnon JG (2004) Blockade of quinolinic acid-induced neurotoxicity by pyruvate is associated with inhibition of glial activation in a model of Huntington's disease. Exp Neurol 187:150-159.

Ryu JK, Choi HB, McLarnon JG (2005) Peripheral benzodiazepine receptor ligand PK11195 reduces microglial activation and neuronal death in quinolinic acid-injected rat striatum. Neurobiol Dis 20:550-561.

Suo Z, Wu M, Citron BA, Gao C, Festoff BW (2003) Persistent proteaseactivated receptor 4 signaling mediates thrombin-induced microglial activation. J Biol Chem 278:31177-31183.

Suzuki T, Hide I, Ido K, Kohsaka S, Inoue K, Nakata Y (2004) Production and release of neuroprotective tumor necrosis factor by $\mathrm{P} 2 \mathrm{X} 7$ receptoractivated microglia. J Neurosci 24:1-7.

Tikka T, Fiebich BL, Goldsteins G, Keinanen R, Koistinaho J (2001) Minocycline, a tetracycline derivative, is neuroprotective against excitotoxicity by inhibiting activation and proliferation of microglia. J Neurosci 21:2580-2588.

Tomas-Camardiel M, Rite I, Herrera AJ, de Pablos RM, Cano J, Machado A, Venero JL (2004) Minocycline reduces the lipopolysaccharide-induced inflammatory reaction, peroxynitrite-mediated nitration of proteins, disruption of the blood-brain barrier, and damage in the nigral dopaminergic system. Neurobiol Dis 16:190-201.

Walker DG, Lue LF, Beach TG (2001) Gene expression profiling of amyloid beta peptide-stimulated human post-mortem brain microglia. Neurobiol Aging 22:957-966.

Wang X, Arcuino G, Takano T, Lin J, Peng WG, Wan P, Li P, Xu Q, Liu QS, Goldman SA, Nedergaard M (2004) P2X7 receptor inhibition improves recovery after spinal cord injury. Nat Med 10:821-827.

Witting A, Walter L, Wacker J, Moller T, Stella N (2004) P2X7 receptors control 2-arachidonoylglycerol production by microglial cells. Proc Natl Acad Sci USA 101:3214-3219. 